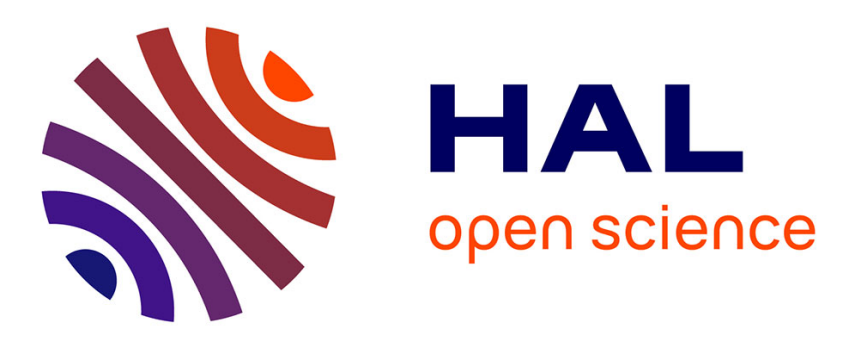

\title{
Numerical Investigations for the Optimization of Serrated Finned-Tube Heat Exchangers
}

\author{
A. Lemouedda, A. Schmid, E. Franz, M. Breuer, A. Delgado
}

\section{To cite this version:}

A. Lemouedda, A. Schmid, E. Franz, M. Breuer, A. Delgado. Numerical Investigations for the Optimization of Serrated Finned-Tube Heat Exchangers. Applied Thermal Engineering, 2011, 31 (8-9), pp.1393. 10.1016/j.applthermaleng.2010.12.035 . hal-00730303

\section{HAL Id: hal-00730303 https://hal.science/hal-00730303}

Submitted on 9 Sep 2012

HAL is a multi-disciplinary open access archive for the deposit and dissemination of scientific research documents, whether they are published or not. The documents may come from teaching and research institutions in France or abroad, or from public or private research centers.
L'archive ouverte pluridisciplinaire HAL, est destinée au dépôt et à la diffusion de documents scientifiques de niveau recherche, publiés ou non, émanant des établissements d'enseignement et de recherche français ou étrangers, des laboratoires publics ou privés. 


\section{Accepted Manuscript}

Title: Numerical Investigations for the Optimization of Serrated Finned-Tube Heat

Exchangers

Authors: A. Lemouedda, A. Schmid, E. Franz, M. Breuer, A. Delgado

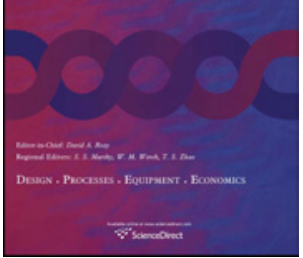

PII:

S1359-4311(11)00004-4

DOI:

10.1016/j.applthermaleng.2010.12.035

Reference: $\quad$ ATE 3359

To appear in: Applied Thermal Engineering

Received Date: 11 August 2010

Revised Date: 6 December 2010

Accepted Date: 30 December 2010

Please cite this article as: A. Lemouedda, A. Schmid, E. Franz, M. Breuer, A. Delgado. Numerical Investigations for the Optimization of Serrated Finned-Tube Heat Exchangers, Applied Thermal Engineering (2011), doi: 10.1016/j.applthermaleng.2010.12.035

This is a PDF file of an unedited manuscript that has been accepted for publication. As a service to our customers we are providing this early version of the manuscript. The manuscript will undergo copyediting, typesetting, and review of the resulting proof before it is published in its final form. Please note that during the production process errors may be discovered which could affect the content, and all legal disclaimers that apply to the journal pertain. 


\title{
Numerical Investigations for the Optimization of Serrated Finned-Tube Heat Exchangers
}

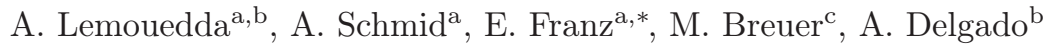 \\ ${ }^{a}$ Department of Process Engineering, Georg-Simon-Ohm University of Applied Sciences, \\ Wassertorstr. 10, D-90489 Nürnberg, Germany \\ ${ }^{b}$ Institute of Fluid Mechanics, Friedrich-Alexander University of Erlangen-Nürnberg, Cauerstr. 4, \\ D-91056 Erlangen, Germany \\ ${ }^{c}$ Department of Fluid Mechanics, Institute of Mechanics, Helmut-Schmidt-University Hamburg, \\ Holstenhofweg 85, D-22043 Hamburg, Germany
}

\begin{abstract}
Helical serrated finned-tubes are well established in many thermal systems. This paper presents the results of numerical calculations carried out for the performance improvement of these devices. The work is divided into three main investigations conducted for Reynolds numbers between $R e=600$ and 2600. The first investigation shows the effect of the fin serration, where a comparison between performances of finned tubes with and without fin serration is presented. Another main investigation is conducted on the effect of fin twisting of the outermost part of the fin on the performance of the serrated finned-tubes. Here, twisting angles considered are between $\beta=0^{\circ}$ and $25^{\circ}$. The third investigation deals with the effect of the number of fin segments per period. Keywords: Heat exchangers; Heat transfer enhancement; Serrated finned-tubes; Segmented fins; Fin twisting.

\section{Introduction}

Due to the widespread utilization of heat exchangers in various daily and industrial applications, the improvement of their performances is of great importance. Usually, more attention and research efforts are devoted to regions where the energy-carrying fluid is a gas since gases have a very low thermal conductivity compared to liquids. Many passive techniques are used to enhance the heat transfer on the gas-side of heat exchangers.
\end{abstract}

\footnotetext{
${ }^{*}$ Corresponding author. Tel: +49 91158801470

Email address: eberhard.franz@ohm-hochschule.de (E. Franz)
} 


\section{Nomenclature}

\begin{tabular}{|c|c|c|c|}
\hline$a$ & thermal diffusivity $\left(\mathrm{m}^{2} / \mathrm{s}\right)$ & \multicolumn{2}{|c|}{ Greek symbols } \\
\hline$A$ & area $\left(m^{2}\right)$ & $\beta$ & fin twisting angle $\left(^{\circ}\right)$ \\
\hline$c_{p}$ & specific heat $(J /(k g \cdot K))$ & $\Delta$ & first grid line spacing $(m)$ \\
\hline$d$ & tube diameter $(m)$ & $\delta_{i j}$ & Kronecker delta \\
\hline$D$ & outer fin diameter $(m)$ & $\eta$ & fan efficiency \\
\hline$e_{v}$ & power input per unit volume $\left(W / m^{3}\right)$ & $\lambda$ & thermal conductivity $(W /(m \cdot K))$ \\
\hline$f$ & vortex shedding frequency & $\mu$ & dynamic viscosity $(P a \cdot s)$ \\
\hline$g_{j}$ & $\begin{array}{l}\text { gravitational acceleration in } j \text {-di } \\
\left(\mathrm{m} / \mathrm{s}^{2}\right)\end{array}$ & $\tau_{i j}$ & stress tensor \\
\hline$h$ & specific enthalpy $(J / k g)$, fin height ( & $\rho$ & density $\left(k g / m^{3}\right)$ \\
\hline$\dot{m}$ & mass flow rate $(\mathrm{kg} / \mathrm{s})$ & & \\
\hline$N$ & number of segments per period & $S u b$ & cripts \\
\hline$p$ & pressure $(P a)$, fin pitch $(m)$ & $f$ & fluid, fin-strip \\
\hline$\dot{q}_{v}$ & heat transfer per unit volume $\left(W / m^{3}\right)$ & in & inlet \\
\hline$s$ & fin thickness $(m)$ & $m$ & mean \\
\hline$S_{d}$ & tube spacing $(m)$ & out & outlet \\
\hline$t$ & time $(s)$ & $s$ & solid, serrated part \\
\hline$T$ & temperature $(\mathrm{K})$ & $t$ & total \\
\hline$u_{i}$ & Cartesian velocity components $(\mathrm{m} / \mathrm{s})$ & $w$ & wall \\
\hline$U$ & velocity component $(\mathrm{m} / \mathrm{s})$ & & \\
\hline$v$ & volume $\left(m^{3}\right)$ & \multicolumn{2}{|c|}{ Dimensionless numbers } \\
\hline$w$ & segment width $(m)$ & $R e$ & Reynolds number \\
\hline$x_{i}$ & $i$-th Cartesian coordinate & $S t$ & Strouhal number \\
\hline$X$ & Cartesian coordinates & & \\
\hline$\Delta P$ & pressure drop $(P a)$ & & \\
\hline$\Delta t$ & time step $(s)$ & & \\
\hline$\Delta T$ & temperature difference $(K)$ & & \\
\hline
\end{tabular}


Among them is the periodic interruption of the growth of the fluid boundary layers close to the heat transfer surfaces. Another technique is the increase of fluid mixing, fluid vorticity and turbulence intensity (see, e.g., [1, 2, 3] ). Webb and Kim [4] provided a detailed summary about the heat transfer enhancement technology.

One of the most popular geometries which ensure the techniques mentioned are the segmented fins also known as serrated fins. Serrated finned-tubes are becoming well established in many thermal systems, especially air-conditioning and boiler economizers. However, compared to other forms of finned-tubes, only a few studies were performed for this family of finned tubes. Among these studies is the one done by Weiermann [5]. He investigated the performance of inline and staggered tube arrangements of steel segmented and plain fin geometries and proposed empirical correlations for both arrangements. Weiermann and Tanborek [6] studied the effect of the arrangement of the thermal performance of segmented tubes. They compared both inline and staggered arrangements and recommended to use the latter one. Additional data about both arrangements for heat recovery systems were presented by Rabas et al. [7]. Eckels and Rabas [8] studied the heat transfer and pressure drop of many finned tube bundle configurations including the serrated finned-tubes. Holtzapple and Carranza [9] and Holtzapple et al. [10] provided friction and heat transfer data for spine finned tubes of copper. Caranza et al. [11] proposed an empirical pressure drop correlation for a spined pipe in cross-flow. The "Extended Surface Corporation of America" (ESCOA) [12] presented a modified version of the correlations of Weiermann [5] in order to obtain better predictive models. ESCOA and Weiermann's correlations for the solid and serrated fin performances were used by Hofmann et al. [14] in order to evaluate the results of their experimental investigations. These experimental studies were carried out for solid and serrated finned-tube bundles for different fin geometries. Martinez et al. [13] conducted experimental investigations on helical serrated finned-tubes and proposed a methodology of designing these devices at an industrial scale. Naess [15] studied the heat transfer and pressure drop in different serrated-fin tube bundles for waste heat recovery applications.

The numerical investigations carried out in this study are a contribution to the research done for the heat transfer enhancement using serrated finned-tubes. Here, a performance comparison between finned-tubes with serrated and with full (non-serrated) fins is presented. A further investigation is conducted in order to see the effect of fin twist- 
ing of the outermost part of the fin on the performance of serrated finned-tubes. This fin twisting is usually produced during the manufacturing process and is in most of the cases unavoidable. To the knowledge of the authors, no previous study was published on this subject. Finally, the effect of the number of fin segments on the performance is investigated.

\section{Simulation Model}

For the different investigations performed, a basic simulation model for three-row finned-tube arrays in a staggered equilateral arrangement is used. This simulation model is depicted in Fig. 1. On each tube, fins with two helical periods (rotations) are assumed to be perfectly fixed as shown in Fig. 1a. The geometrical details of a unit cell (a tube and a fin fixed on it) are shown in Fig. 2 for both cases with serrated and with full fins.

In the following investigations, the basic simulation model with the details given in Table 1 is used as a reference model for comparison purposes. The corresponding changes to each case studied are prescribed accordingly.

The boundary conditions adopted are presented in Fig. 1a. The top, bottom and sides of the model are assumed to be adiabatic slip walls. The tubes are no-slip walls at a fixed temperature $\left(T_{w}=350 K\right)$. The conjugate heat transfer analysis is considered in the simulations performed. Therefore, the solid-fluid interface between the fins and the energy-carrying fluid are no-slip walls where the heat flux and the temperature are continuous across the boundary plane. At the inlet, a uniform velocity $U=U_{i n}$ and a fixed temperature $T_{i n}=300 \mathrm{~K}$ are assumed. Moreover, a constant pressure boundary condition is used at the outlet. In this study, the investigations are performed for Reynolds numbers between 600 and 2600. Here, the Reynolds number is calculated based on the inlet velocity $U_{i n}$ and the tube diameter $d$. Due to the high computational costs required and due to their comparative nature, some investigations are performed only for some specific Reynolds numbers which are mentioned in the corresponding sections (Section 5.1 and 5.3). 


\section{Methodology}

\subsection{Governing Equations of the Fluid Flow and Heat Transport}

The flow and heat transfer computations are performed for a three-dimensional, time-dependent flow of air. The governing equations for the compressible fluid flow are:

Continuity equation

$$
\frac{\partial \rho}{\partial t}+\frac{\partial\left(\rho u_{i}\right)}{\partial x_{i}}=0
$$

Momentum equation

$$
\rho\left[\frac{\partial u_{j}}{\partial t}+u_{i} \frac{\partial u_{j}}{\partial x_{i}}\right]=-\frac{\partial p}{\partial x_{j}}-\frac{\partial \tau_{i j}}{\partial x_{i}}+\rho g_{j} \quad(i, j=1,2,3)
$$

Energy equation

$$
\rho\left[\frac{\partial h}{\partial t}+u_{i} \frac{\partial h}{\partial x_{j}}\right]=\frac{\partial}{\partial x_{i}}\left[\lambda \frac{\partial T}{\partial x_{i}}\right]-\tau_{i j} \frac{\partial u_{j}}{\partial x_{i}}+\frac{\partial p}{\partial t}+u_{i} \frac{\partial p}{\partial x_{i}} .
$$

Here $\rho$ denotes the fluid density, $t$ the time, $u_{i}$ the velocity component in $i$ direction and $x_{i}$ the Cartesian coordinate. $p$ is the pressure, $g_{j}$ is the gravitational acceleration. $h$ is the specific enthalpy, $T$ is the temperature and $\lambda$ is the thermal conductivity coefficient. $\tau_{i j}$ stands for the viscous stress tensor and can be expressed for a Newtonian fluid as:

$$
\tau_{i j}=-\mu\left(\frac{\partial u_{i}}{\partial x_{j}}+\frac{\partial u_{j}}{\partial x_{i}}\right)+\frac{2}{3} \delta_{i j} \frac{\partial u_{k}}{\partial x_{k}}
$$

where $\mu$ is the dynamic viscosity and $\delta_{i j}$ is the Kronecker delta function.

Although the flow is only weakly compressible, the advantage of the application of the compressible set of equations is that buoyancy effects are directly included and thus do not need modeling based on the Boussinesq approximation.

For external flows across cylindrical tubes, the boundary layer on the cylinders remains laminar for $R e \leq 2 \cdot 10^{5}$ and transition may occur in the free shear-layers behind the cylinder (see [16] for more details). Therfore, the flow is assumed in this study to be laminar. Owing to the moderate Reynolds number range considered (i.e., $600 \leq$ $R e \leq 2600)$, there is no need to take a subgrid-scale or even a RANS turbulence model 
into account. As verified by preliminary simulations of comparable cases [17, 18], it is fully sufficient to solve the Navier-Stokes equations in an instantaneous manner on an adequate numerical grid. Thus, the present computations can be considered as large-eddy simulations without a subgrid-scale model or as coarse-grid direct numerical simulations.

As already mentioned, in this study the conjugate heat transfer is considered. In this model, the calculation of the conduction in a solid region is coupled with the calculation of the temperature distribution in the working fluid flowing over or through this solid region. In addition to the solution of the Navier-Stokes equations for the fluid region, the heat transport equation is solved for the solid part. For the case without a heat source and a constant thermal conductivity for the solid region as in this study, the heat equation is presented as follows:

$$
\frac{1}{a} \frac{\partial T}{\partial t}=\frac{\partial}{\partial x_{i}}\left(\frac{\partial T}{\partial x_{i}}\right)
$$

Here $a$ is the thermal diffusivity with $a=\lambda / \rho c_{p}$, where $c_{p}$ denotes the specific heat. Eq. (5) for a solid region with constant properties can be obtained from Eq. (3) by setting the velocity (including $\tau_{i j}$ ) and the pressure derivatives to zero.

\subsection{Numerical Settings}

In these investigations, three-dimensional transient calculations are carried out for the flow of air over the finned tubes. The energy-carrying fluid (air) is assumed to behave like an ideal gas. The fins are assumed to be with constant properties and in copper. For the solution of the governing equations presented in Section 3.1, the finite-volume-based CFD code "STAR-CCM+ (V.4)" [19] is used. A coupled implicit solver with second-order accurate upwind schemes is employed for both space and time discretization.

The grid-dependency is checked for seven different unstructured grids with polyhedral cells and prism layers close to the no-slip walls. The grids checked have 6.1, 6.9, 8.1, 8.2, 8.5, 10 and 10.2 millions cells, respectively. As expected, the error in the heat transfer rate and the power input per unit volume decreases by refining the grid. The error between the finest grid having 10.2 millions cells and the grid having 8.1 millions cells was less than $1.2 \%$ for the heat transfer rate per unit volume and less than $0.9 \%$ for the power input. Therefore, the settings of the grid of the latter (8.1 million cells) 
were used for further investigations in the current study. Fig. 3 shows the grid used on an horizontal plane section in the middle of the simulation model. In this grid, six prism layers close to the walls were used in the fluid region and three layers in the solid region. The mean distance of the first grid lines in the normal direction to the walls is $\Delta_{f} / d=16 \cdot 10^{-4}$ for the fluid region and $\Delta_{s} / d=4 \cdot 10^{-4}$ for the solid region.

\section{Performance Assessment Method}

In the current work, the performance assessment of different cases investigated is done based on the direct plot of the heat transfer rate reduced to the volume of the heat exchanger $\left(\dot{q}_{v}\right)$ versus the required power input $\left(e_{v}\right)$ also reduced to the volume of the heat exchanger. The optimal designs are selected based on the maximization of heat transfer per unit volume with a minimization of the power input. More details on this assessment method are given in [20,21].

The heat transfer per unit volume is calculated as follows:

$$
\dot{q}_{v}=\frac{\dot{m}_{f} c_{p}\left(T_{\text {out }}-T_{\text {in }}\right)}{v},
$$

with

$$
T_{\text {out }}=\frac{\int_{\text {out }} u T d A_{\text {out }}}{\int_{\text {out }} u d A_{\text {out }}}
$$

Here, $v$ is the design volume, $\dot{m}_{f} c_{p}$ is the heat capacity rate, $T_{i n}$ is the bulk inlet temperature considered as constant and $T_{\text {out }}$ is the bulk temperature at the outlet. $u$ denotes the velocity in the streamwise direction and $A_{\text {out }}$ the outlet cross-section.

The power input per unit volume is given as follows:

$$
e_{v}=\frac{\dot{m}_{f} \Delta P}{\rho_{m} \eta v}
$$

where $\rho_{m}$ denotes the average of the density values at the inlet and outlet, $\Delta P$ is the total pressure drop between inlet and outlet and $\eta$ is the fan efficiency here assumed to be 0.8. Since in Eq. (8) except $\Delta P$ all other variables are either constants or have a negligible variation, the power input per unit volume $e_{v}$ is a direct measure for the pressure drop in the heat exchanger.

For the cases investigated, the fluid flow is time dependent and has a periodical variation as depicted, e.g., in Fig. 4. This figure shows the instantaneous velocity magnitude in 
an horizontal plane section in the middle of the simulation model. It demonstrates the existence of vortex shedding especially behind the tubes. Therefore, equations (6)-(8) are evaluated based on the time-averaged quantities. The time-averaging was done for more than 80 shedding periods and was started after the flow has reached a statistically fully developed state. In this study, the frequency of the vortex generation is calculated as follows:

$$
f=\frac{S t U_{\text {in }}}{d}
$$

with the assumption that the Strouhal number is about $S t=0.2$ and considering the tube diameter $d$ as a reference length.

\section{Results and Discussion}

CFD calculations are carried out in order to see the effect of the fin serration, the fin twisting and the number of fin segments per period for the helical serrated finned-tubes. The results obtained are reported in the following subsections.

\subsection{Effect of fin serration}

The effect of the fin serration on the heat transfer and the pressure drop is investigated first. For that purpose, the performances of three different configurations are compared. The first configuration is the reference model with serrated finned-tubes presented in Section 2. In the two other configurations, the serrated fins are replaced with full fins (without segmentation in the fin). Figs. $2 \mathrm{~b}$ and $\mathrm{c}$ show the serrated and the full fin used, respectively.

The fins in the second configuration have the same fin height as in the reference model. However, this configuration (with full fins) has $12.3 \%$ higher area than the reference model which contains gaps between the segments with a uniform spacing (see Figs. 2b). In the third configuration, the fins have the same heat transfer area as the serrated fins of the reference model. Their height is slightly lower than that of the serrated fins of the reference model. The fin height of the serrated model is 1.09 times the fin height of the third model.

The performance plot for the three configurations investigated is depicted in Fig. 5 for Reynolds numbers 1000, 1800 and 2200, respectively. It is clear that for the same heat transfer area, the case with serrated fins delivers better performances than the case with full fins. The configuration with serrated fins shows an about $9 \%$ better heat 
transfer rate for the same power input than the configuration with full fins having the same heat transfer area.

For the same fin height, even though the model with full fins has a higher area than the reference model with serrated fins, the performances of both configurations are close to each other. However, for a similar performance, the configuration with serrated fins has the advantage of savings in material of $12.3 \%$ compared to the case with full fin.

Fig. 5 shows that for a given Reynolds number (for clarity, the points related to $R e=$ 1800 are surrounded by a green circle as an example), the heat transfer rate for the case of serrated fins (reference model) is higher than both cases with full fins. This is due to the refreshment of the boundary layer ensured by the segmentation of the fins. However, the full fins have smoother geometry than the serrated fins. Therefore, the corresponding flow resistance is lower which leads to lower pressure losses and hence lower power inputs required for the case of full fins compared to the case of the serrated fins.

Furthermore, by comparing the results obtained for both cases with full fins, it is obvious that increasing the area of the full fin yields a better performance within the range of the fin heights studied.

\subsection{Effect of fin twisting}

There are many ways of producing serrated finned-tubes. One of the well-established methods is the wrapping of a serrated fin strip helically around the circumference of each tube and fixing this strip continuously. This fixation is generally ensured by welding or brazing depending on the metals of the tubes and fin strip. Before its fixation on the tube, the fin strip is cut (or serrated) at equally spaced intervals. As the fin strip is wrapped around the tube, the outer part spreads opening the segments like a daisy.

Due to the mechanical cut of the fins, a twisting of the segments of the serrated fins occurs when the strip fin is wrapped around the tube. The level of this twisting, i.e., the fin angle varies depending on factors such as the way and sharpness of the cut, the fin dimensions, the metal used and other factors.

In this section, the effect of the fin twisting is investigated. For that purpose, the basic simulation model is used for configurations with six different fin angles $\beta=0^{\circ}, 5^{\circ}$, $10^{\circ}, 15^{\circ}, 20^{\circ}$ and $25^{\circ}$, respectively. In these investigations, only the outermost part of the segments of the serrated fin is twisted. The continuous part of the fin (the non 
serrated part) is similar for all configurations (see Fig. 6).

The performance plot for different configurations is depicted in Fig. 7. For more clarity, parts $I$ (for $R e$ between 600 and 1800) and $I I$ (for Re between 2200 and 2600) of this figure are zoomed in and presented in Figs. 8a and b, respectively. These figures show that the configurations with fin angles $\beta=5^{\circ}$ and $10^{\circ}$ have generally better performances than the case without fin twining $\left(\beta=0^{\circ}\right)$. However, the configurations with fin angles higher than $15^{\circ}$ (i.e., with $\beta=20^{\circ}$ and $25^{\circ}$ ) have worse performance than the case without fin twisting. The configuration with $\beta=15^{\circ}$ shows better performances than the case without twisting only for high Reynolds numbers $(R e \geq 1800)$ visible in Fig. 8b.

Fig. 9 shows the time-averaged velocity magnitude and velocity vectors on a vertical plane section. It demonstrates that the fluid twisting increases the contact between the fin segments and the fluid of the mainstream flow. Moreover, the level of vorticity and fluid mixing is also increased in the case of twisted fins. Fig. 10 shows the streamlines and the time-averaged temperatures for cases without fin twisting $\left(\beta=0^{\circ}\right)$ and a case with twisting $\left(\beta=25^{\circ}\right)$. It can be seen that the fluid mixing, especially in the wake regions behind the tubes, is higher for the case of twisted fins.

These two effects of the fin twisting lead to an increase of the heat transfer rate. The reason for the higher performances in the case of moderate angles, i.e., $\beta=5^{\circ}$ and $10^{\circ}$ compared to the cases with high twisting angles, i.e., $\beta=20^{\circ}$ and $25^{\circ}$ is that in the cases of moderate angles the twisting does not create a dominant obstacles as in the case of the high angles. In the case of strong fin twisting with angles of $\beta=20^{\circ}$ and $25^{\circ}$, the heat transfer is increased, but with a greater increase in the pressure drop.

\subsection{Effect of the number of fin segments}

The effect of the number of segments in a period on the performance of the serrated finned-tubes is also investigated. For that purpose, the basic model is used with three different number of segments, 19, 39 (the reference model) and 79 segments per period, respectively. Fig. 11 shows the performance plot of the three cases investigated for Reynolds numbers 1000, 1800 and 2200, respectively. It is obvious from this plot that the performance increases with increasing the number of segments per period. For a given power input $e_{v}$ which is directly related to the pressure drop $\Delta P$ as mentioned above, the case with higher number of segments per period has the higher heat transfer rate. The reason is that the increase of the number segments per period leads to 
the increase of the interruption of the boundary layer close to heat transfer surfaces. This results in a higher heat transfer rate as confirmed by Fig. 12 which shows the time-averaged temperature distribution in the fins for cases with different number of segments. The fins are cooled by the relatively cold air. The high temperatures in the fins are in the wake regions behind the tubes. These regions are characterized by a low heat transfer rate between fins and the relatively hot fluid which gets trapped in these regions and poorly mixes with the mainstream flow (see Fig. 4). In Fig. 12, generally the temperature of the fins decreases (better heat transfer rate) by increasing the number of fin segments.

\section{Conclusions}

The numerical investigations carried out in this study show the advantage of serrated fins in improving the performance of finned tubes. This is mainly due to the fact that the interruption of fins in these devices improves the re-build of the boundary layer close to heat transfer surfaces and increases the level of fluid mixing in the flow domain.

The results obtained show that for the same heat transfer area, the serrated fin tubes

have better performances than the full fins. In the current investigations it has also been shown that contrarily to what many manufacturers think, the fin twisting which results from the production process has not always a negative impact on the performance of the serrated finned-tubes. It has been found that no extra work is needed in order to eliminate this twisting if the angles are in the range $\left.] 0^{\circ}, 10^{\circ}\right]$. However, twisting angles greater than $15^{\circ}$ result in a deterioration of the serrated finned-tube performance. This is mainly due to the higher power inputs, i.e., pressure drop associated owing to the high flow resistance that they produce. Furthermore, the increase of the number of fin segments per period leads to more boundary layer interruption and more fluid mixing. This generally improves the performance of the serrated finned tubes.

\section{Acknowledgments}

The project was financially supported by the "Bayerisches Staatsministerium für Wissenschaft, Forschung und Kunst" within the framework of the "Kompetenznetzwerk 
für Technisch-Wissenschaftliches Hoch- und Höchleistungsrechnen in Bayern (KONWIHR II)". The computations were carried out on the computer clusters of the "Regionales Rechenzentrum Erlangen". All kinds of support are gratefully acknowledged. 


\section{References}

[1] F. Dupont, C. Gabillet and P. Bot, Experimental study of the flow in a compact heat exchanger channel with embossed-type vortex generators, Journal of Fluids Engineering (ASME), 125 (2003) 701-709.

[2] G. Biswas, N.K. Mitra and M. Fiebig, Heat transfer enhancement in fin-tube heat exchangers by winglet type vortex generators, International Journal of Heat and Mass Transfer, 37 (1994) 283-291.

[3] M.C. Gentry and A.M. Jacobi, Heat transfer enhancement by delta-wing-generated tip vortices in flat-plate and developing channel flows, Journal of Heat Transfer (ASME), 124 (2002) 1158-1168.

[4] R.L. Webb, N-H. Kim, Principles of Enhanced Heat Transfer, Taylor \& Francis, 2005.

[5] C. Weiermann, Correlations ease the selection of finned tubes, Oil Gas Journal, 74 (1976) 94-100.

[6] C. Weiermann, J. Taborek and W.J. Marner, Comparison of inline and staggered banks of tubes with segmented fins, AIChE Symposium, 74 (174) (1978) 39-46.

[7] T.J. Rabas, G.A. Myers, P.W. Eckles, Comparison of the thermal performance of serrated high-finned tubes used in heat recovery systems, Heat Transfer in Waste Heat Recovery and heat Rejection Systems ASME Symposium, HTD 59 (1986) $33-40$.

[8] P.W. Eckels and T.J. Rabas, Heat transfer and pressure drop performance of finned tube bundles, Int. Journal of Heat Transfer, 107 (1985) 205-213.

[9] M.T. Holtzapple and R.G. Carranza, Heat transfer and pressure drop of spined pipe in cross flow, Part I: Pressure drop studies, ASHRAE Transactions, 92 (2) (1990) 122-129.

[10] M.T. Holtzapple, A.L. Allen and K. Lin, Heat transfer and pressure drop of spined pipe in cross flow, Part III: Heat Transfer studies, ASHRAE Transactions, 92 (2) (1990) 130-135. 
[11] R.G. Carranza and M.T. Holtzapple, A generalized correlation for pressure drop across spined pipe in cross-flow, Part I, ASHRAE Transactions, 97 (2) (1991) 122-129.

[12] V. Ganpathy, Industrial boilers and heat recovery steam generators: Design applications and calculations, First Edition, Marcel Dekker, New York, 2003.

[13] E. Martinez, W. Vicente, M. Salinas und G. Soto, Single-phase experimental analysis of heat transfer in helically finned heat exchanger, Taylor \& Francis, 2005.

[14] R. Hofmann, F. Frasz and K. Ponweiser, Performance evaluation of solid and serrated finned-tube bundles with different fin geometries in forced convection, Proceedings of the Fifth European Thermal Sciences Conference, The Netherlands, 2008.

[15] E. Naess, Heat and pressure drop in serrated-fin tube bundles for waste heat recovery applications, Proceedings of the Sixth World Conference on Experimental Heat Transfer, Japan, No. 1-a-14, 2005.

[16] F. P. Incorpera and D. P. DeWitt Fundamentals of Heat and Mass Transfer. Fifth Ed., John Wiley and Sons, New York, 2002.

[17] A. Lemouedda, M. Breuer, E. Franz, T. Botsch, Optimization of the angle of attack of delta-winglet vortex generators in a plate-fin-and-tube heat exchanger Int. Journal of Heat and Mass Transfer, 53 (2010) 5386-5399.

[18] M. Breuer, Direkte Numerische Simulation und Large-Eddy Simulation turbulenter Strömungen auf Hochleistungsrechnern. Habilitationsschrift, Universität Erlangen-Nürnberg, Berichte aus der Strömungstechnik, ISBN 3-8265-9958-6, Shaker, 2002.

[19] Manual of STAR-CCM+, cd-adapco.com, 14.02.2010.

[20] N. Sahiti, F. Durst, A. Dewan, Strategy for selection of elements for heat transfer enhancement, Int. Journal of Heat and Mass Transfer, 49 (2006) 3392-3400.

[21] N. Sahiti, A. Lemouedda, D. Stojkovic, F. Durst, E. Franz, Performance comparison of pin fin in-duct flow arrays with various pin cross-sections, Applied Thermal Engineering, 26 (2006) 1176-1192. 


\section{Figure Captions}

Figure 1: Simulation model used.

Figure 2: Geometrical details of a unit cell.

Figure 3: Grid used on an horizontal plane section at the middle of the simulation model with a zoom of the fin region

Figure 4: Velocity magnitude on an horizontal plane section at the middle of the simulation model.

Figure 5: Performance plot of cases with and without fin serration.

Figure 6: Serrated fins used with and without twisting.

Figure 7: Performances of configurations with different fin angles.

Figure 8: Zoom in of parts $I$ and $I I$ of Fig. 7.

Figure 9: Time-averaged velocity magnitude and vectors on a vertical plane section across the serrated fins.

Figure 10: Streamlines and time-averaged temperatures for cases with and without fin twisting.

Figure 11: Performance plot for configurations with different number of segments per period and different Reynolds numbers.

Figure 12: Time-averaged temperature distribution in the fins for different number of segments per period. 


\section{Figures}

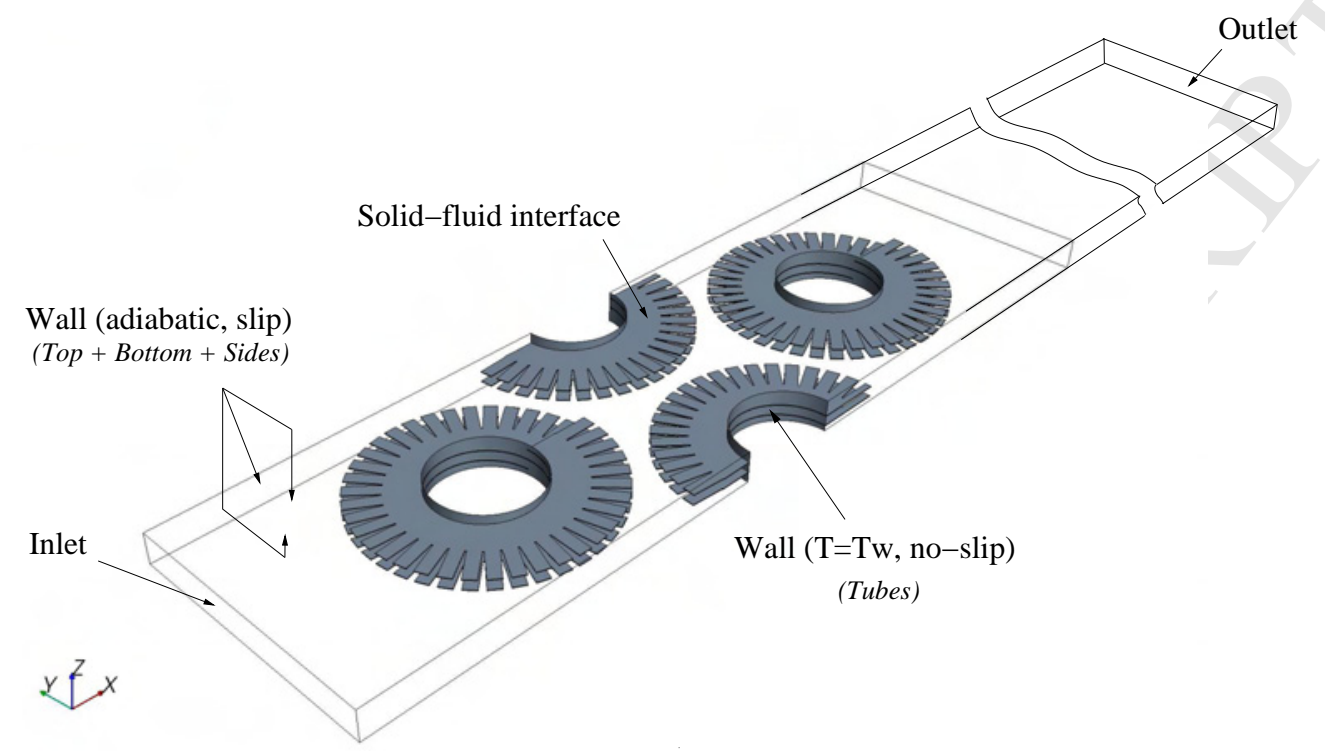

(a) Simulation model with the boundary conditions adopted

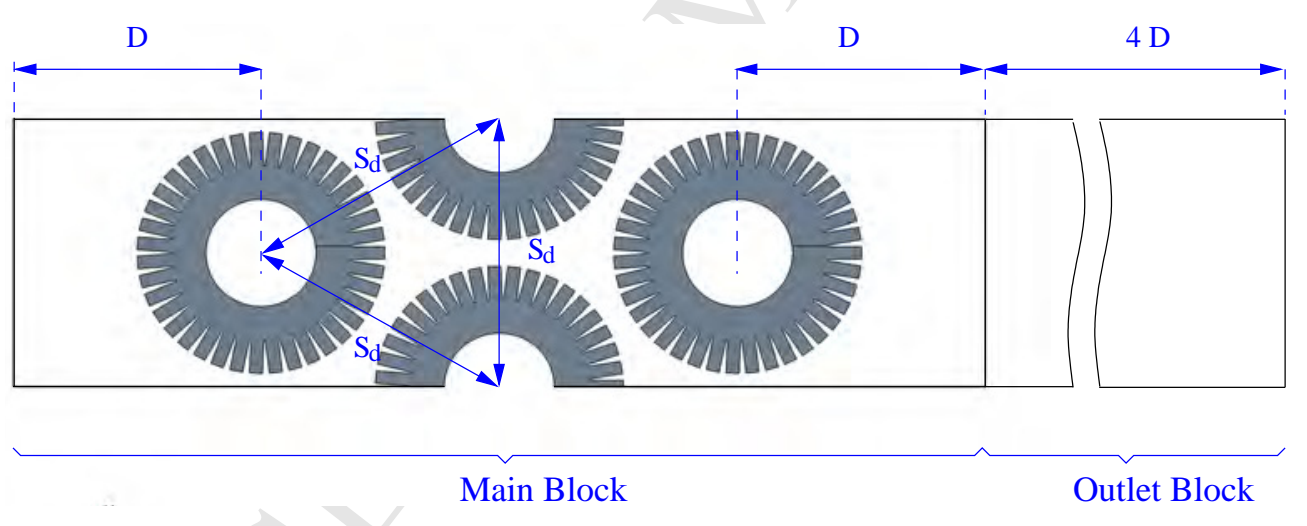

(b) Top view of the simulation model

Figure 1: Simulation model used. 


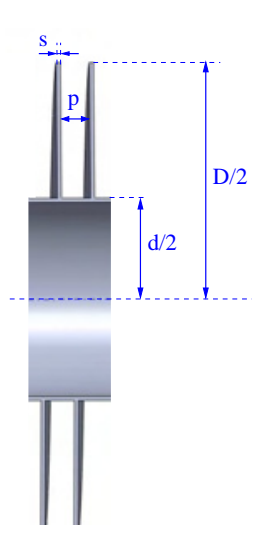
(a) Cut in a unit
cell

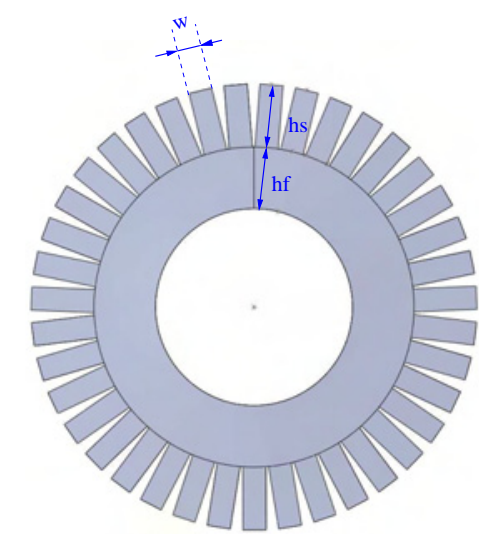

(b) Case of serrated fin

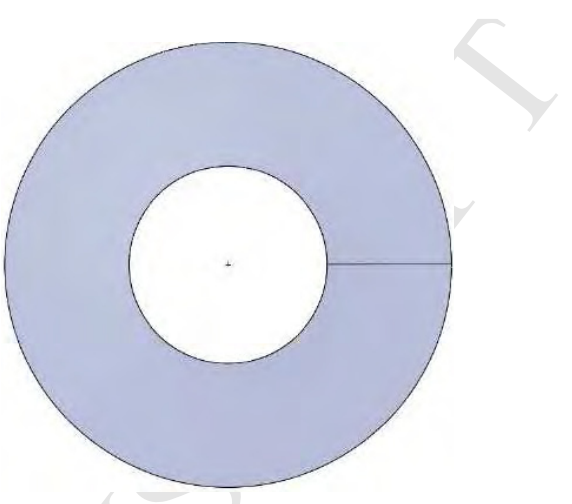

(c) Case of full fin

Figure 2: Geometrical details of a unit cell. 


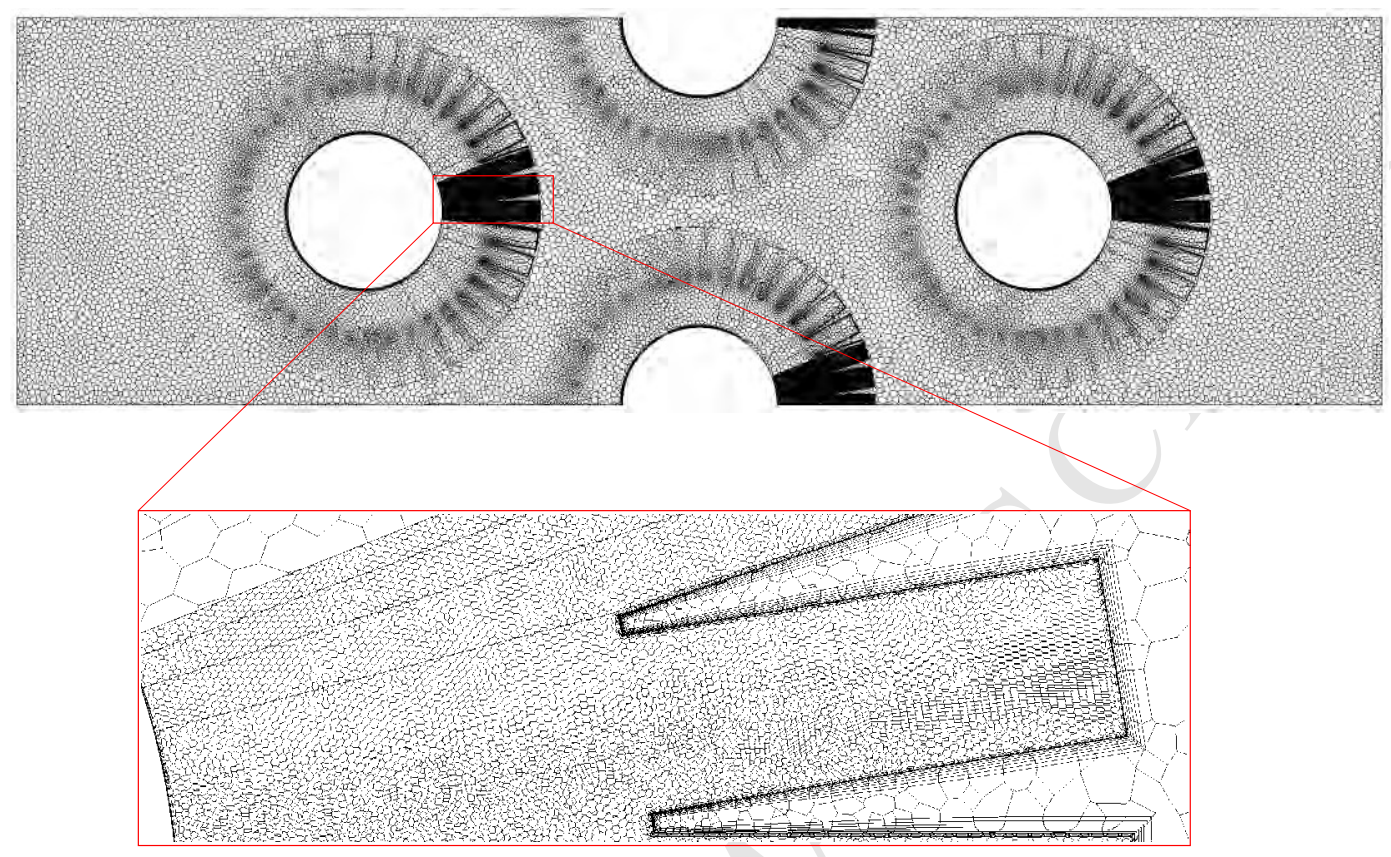

Figure 3: Grid used on an horizontal plane section at the middle of the simulation model with a zoom of the fin region. 

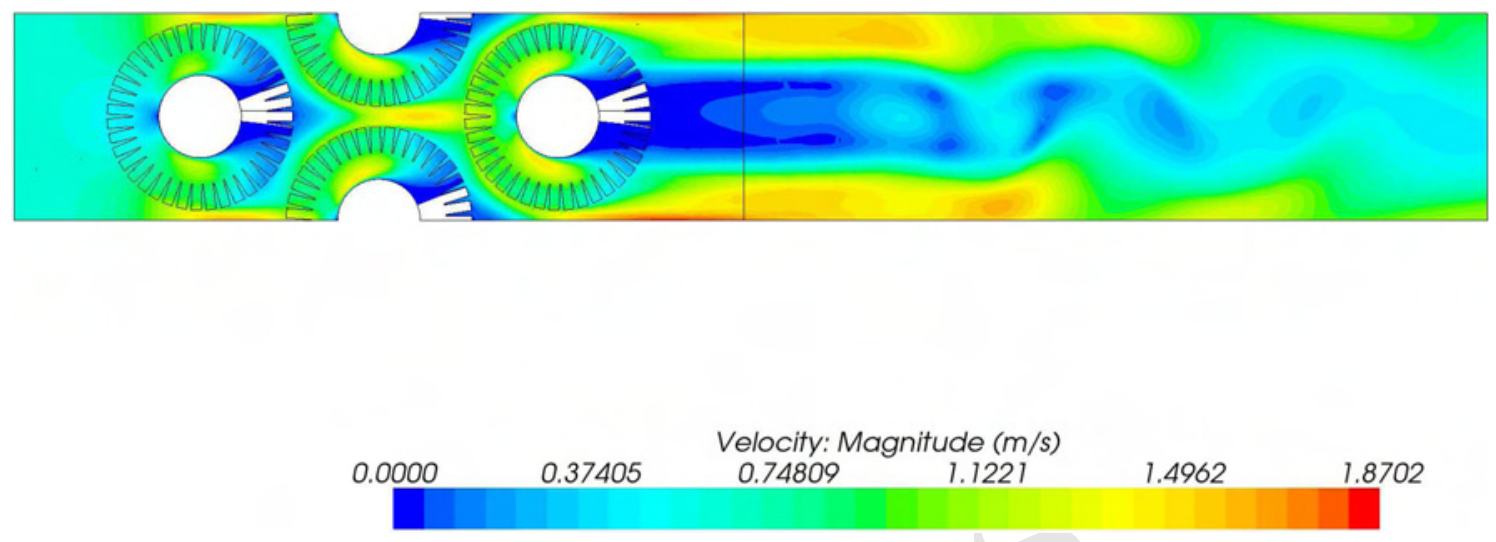

Figure 4: Velocity magnitude on an horizontal plane section at the middle of the simulation model. 


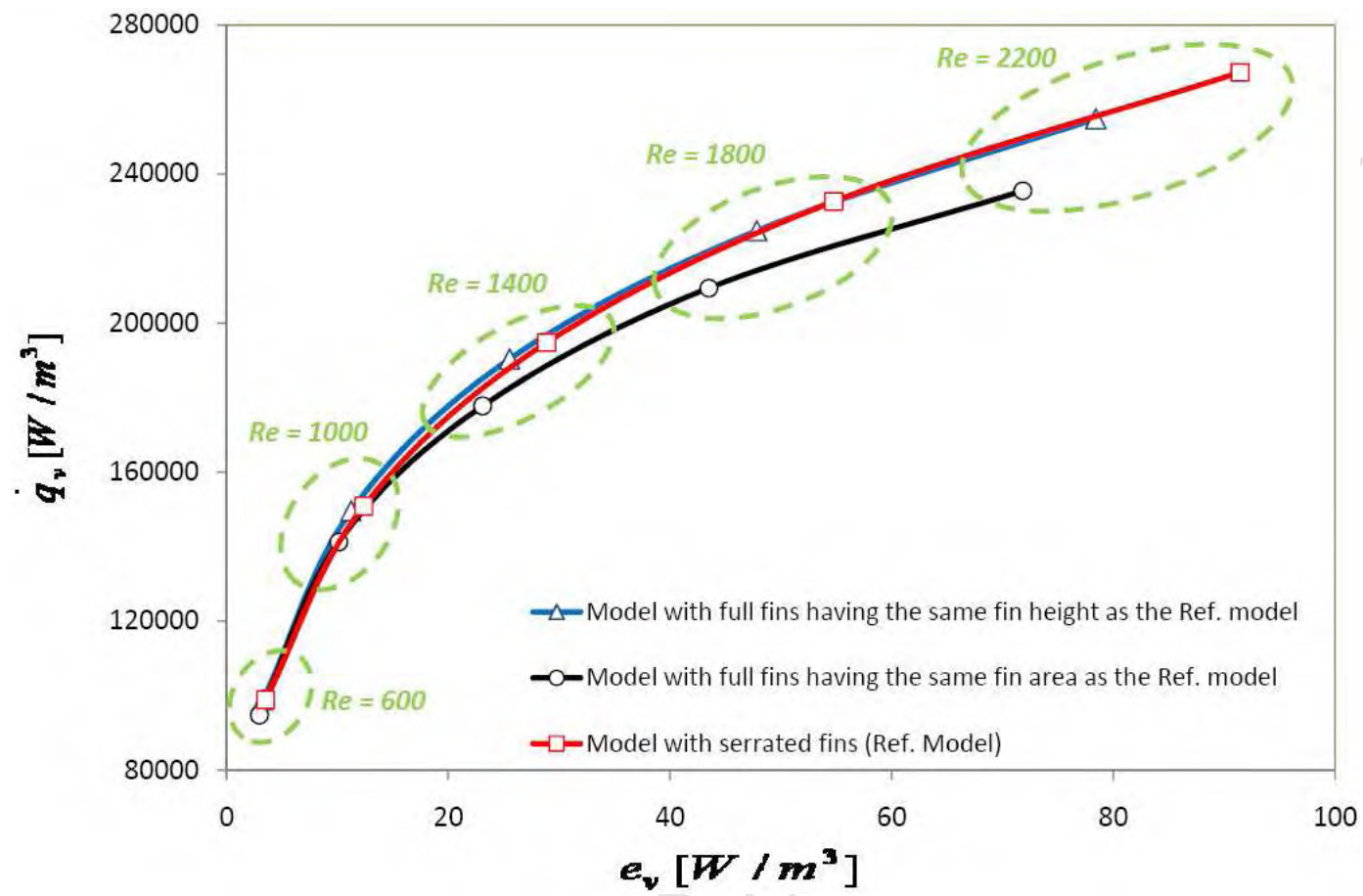

Figure 5: Performance plot of cases with and without fin serration. 


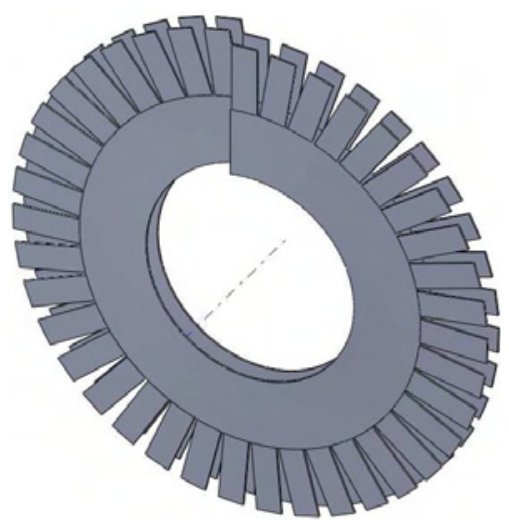

(a) Serrated fin without twisting

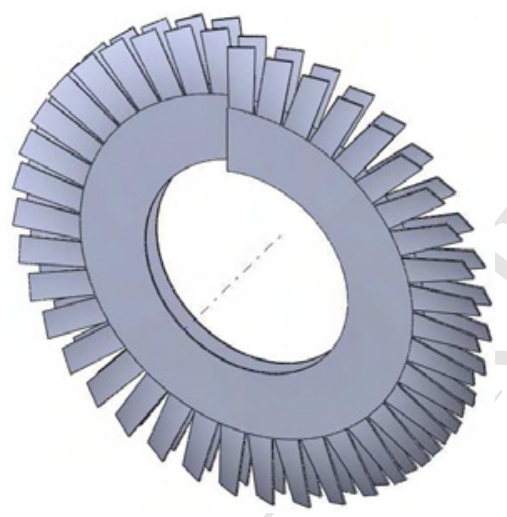

(b) Serrated fins with twisting

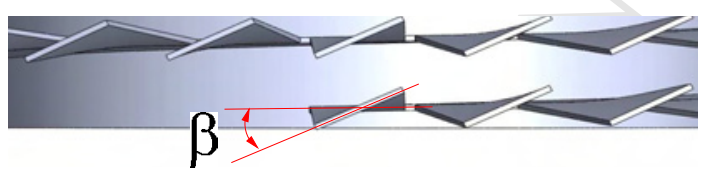

(c) Twisting of the most outer part of the fin

Figure 6: Serrated fins used with and without twisting. 


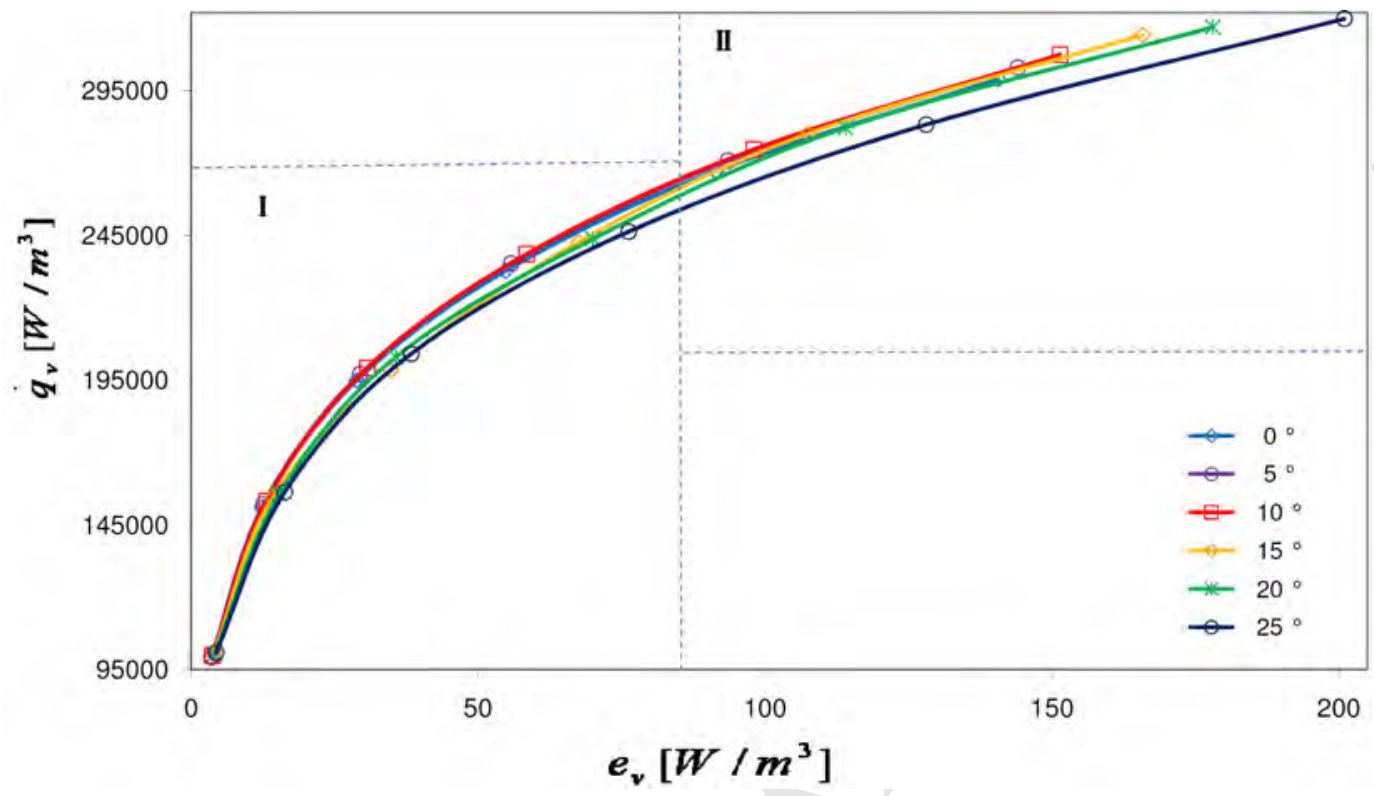

Figure 7: Performances of configurations with different fin angles. 


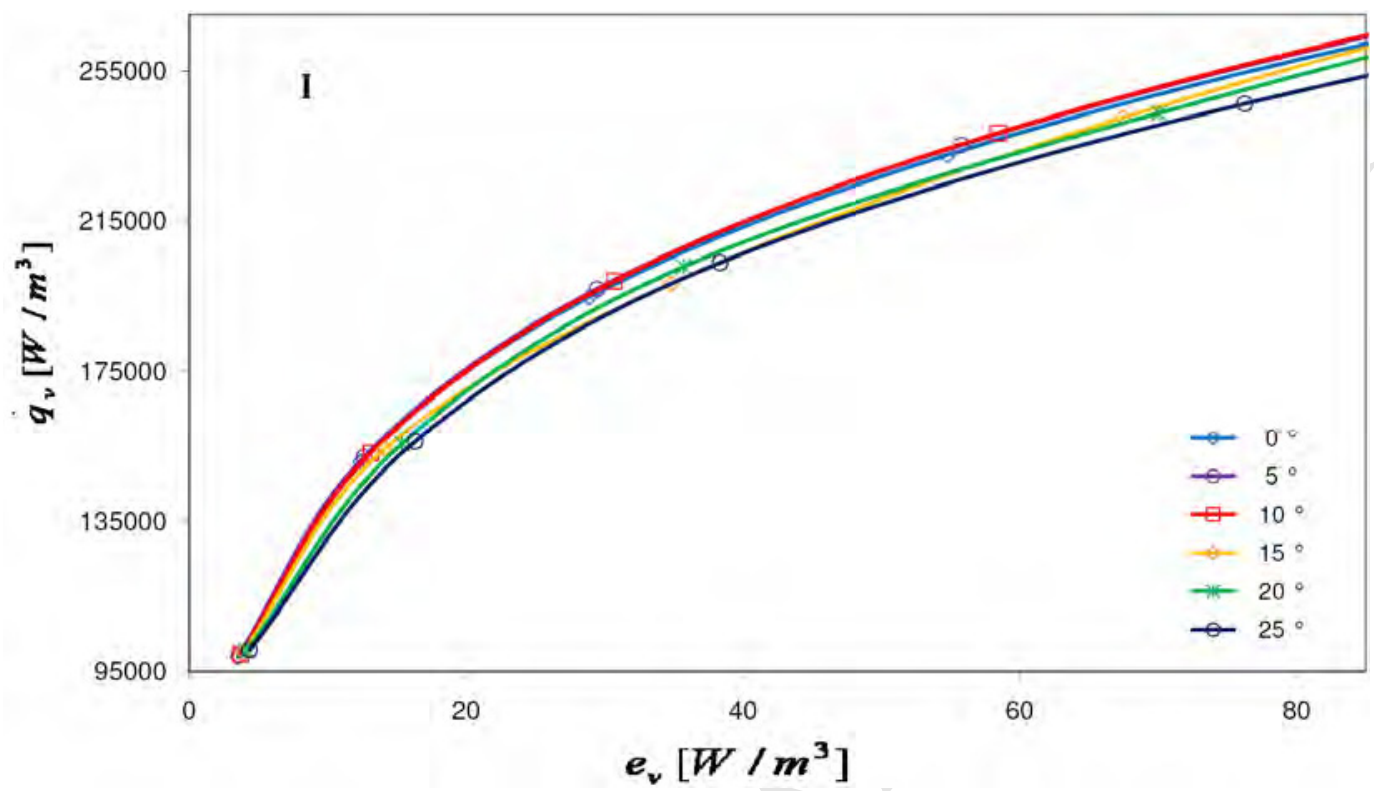

(a) Part $I$

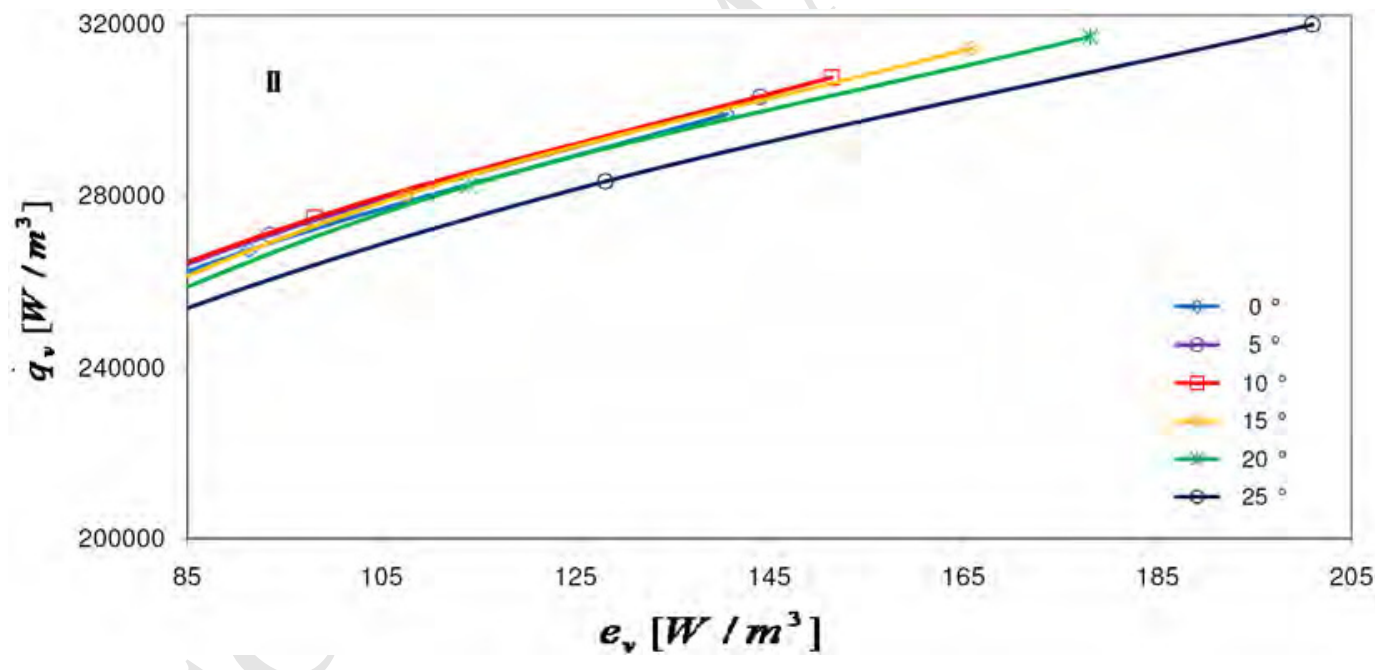

(b) Part II

Figure 8: Zoom in of parts $I$ and $I I$ of Fig. 7. 

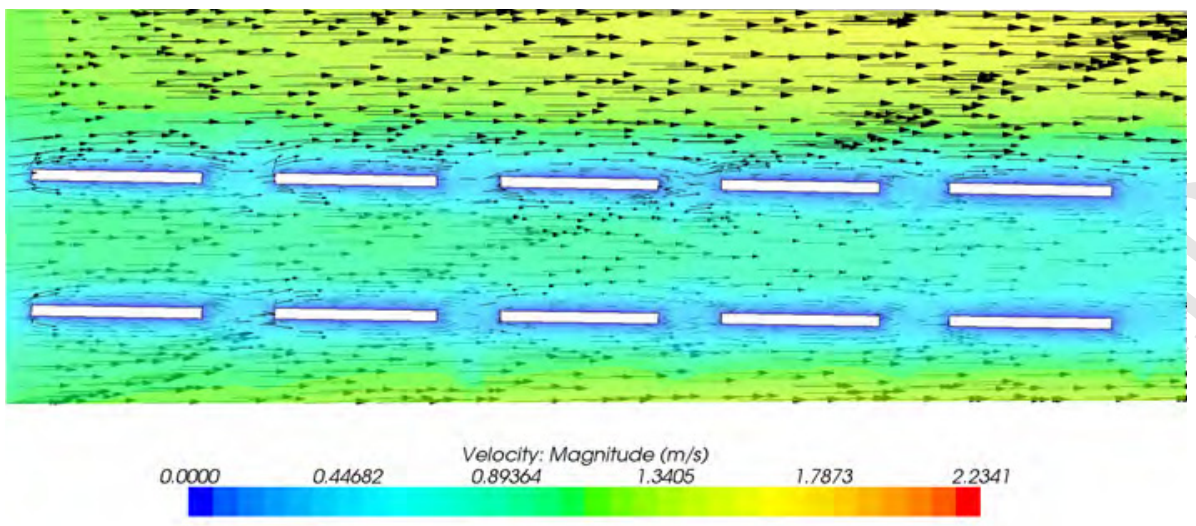

(a) Serrated fin without twisting
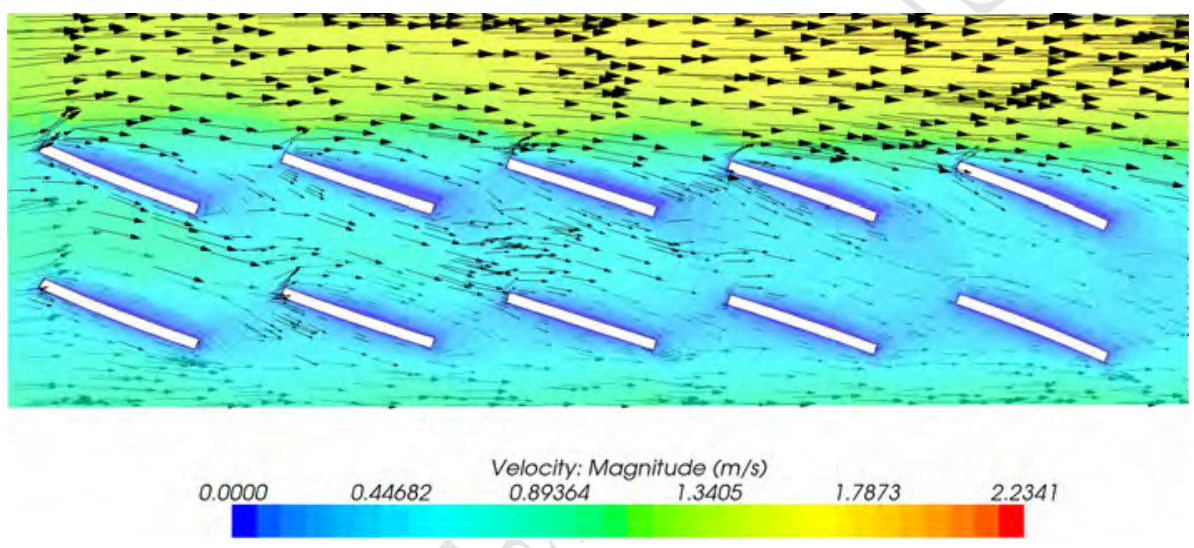

(b) Serrated fins with twisting

Figure 9: Time-averaged velocity magnitude and vectors on a vertical plane section across the serrated fins. 

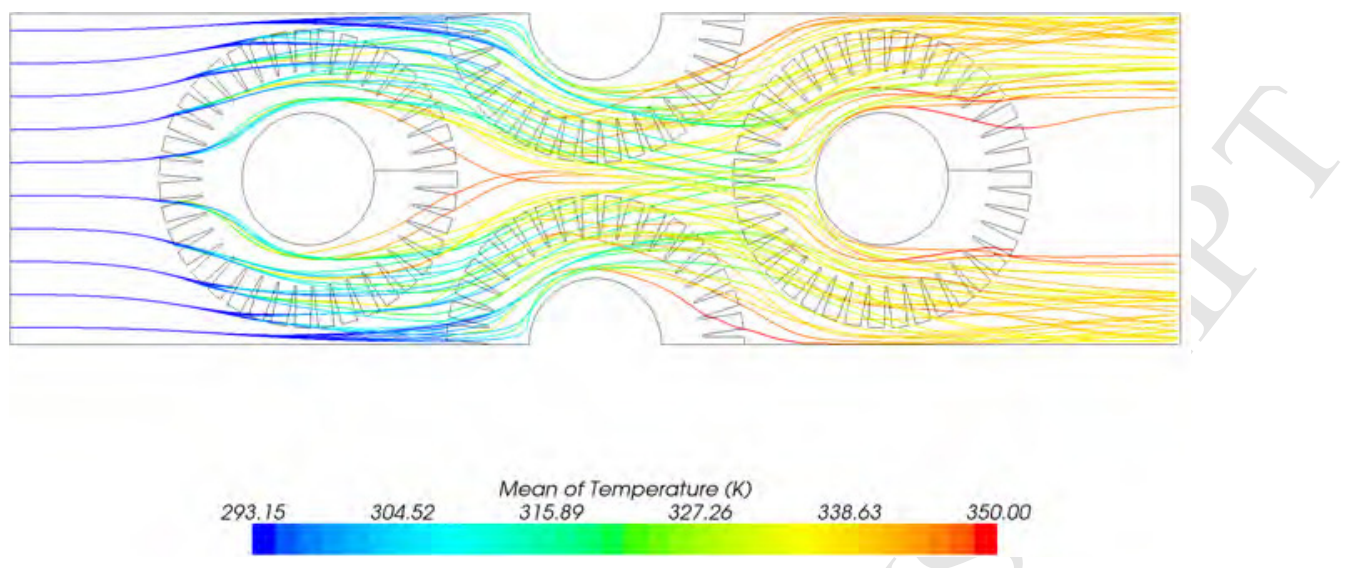

(a) $\beta=0^{\circ}$
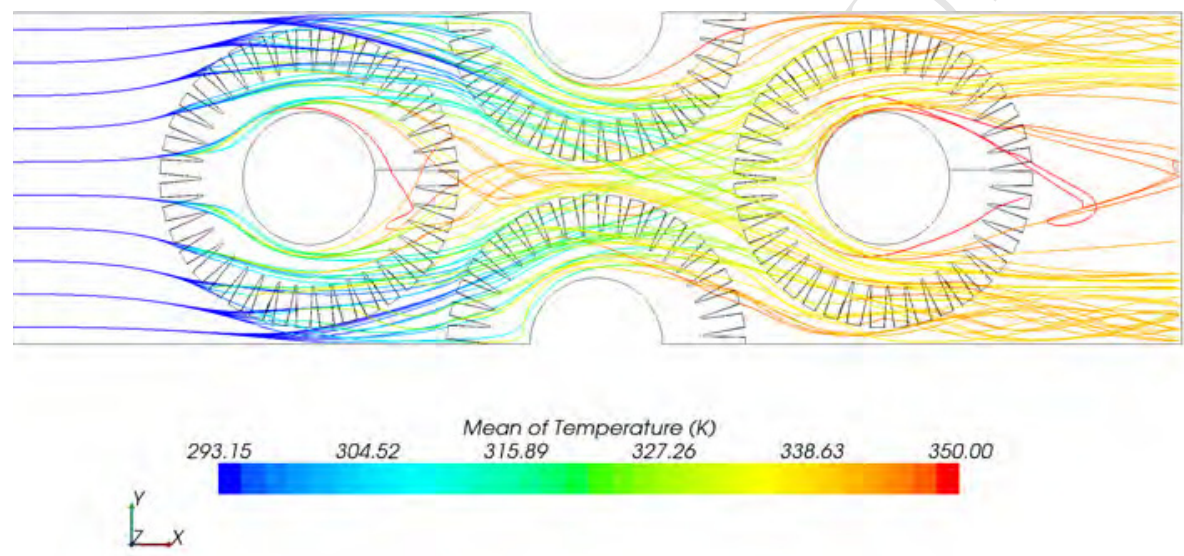

(b) $\beta=25^{\circ}$

Figure 10: Streamlines and time-averaged temperatures for cases with and without fin twisting.

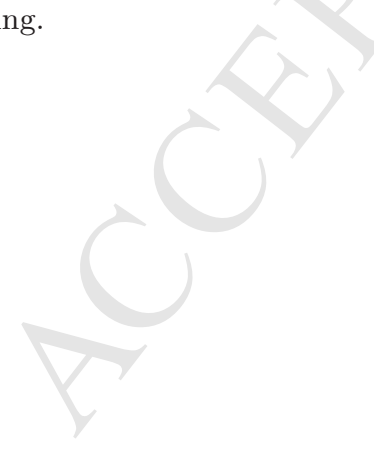




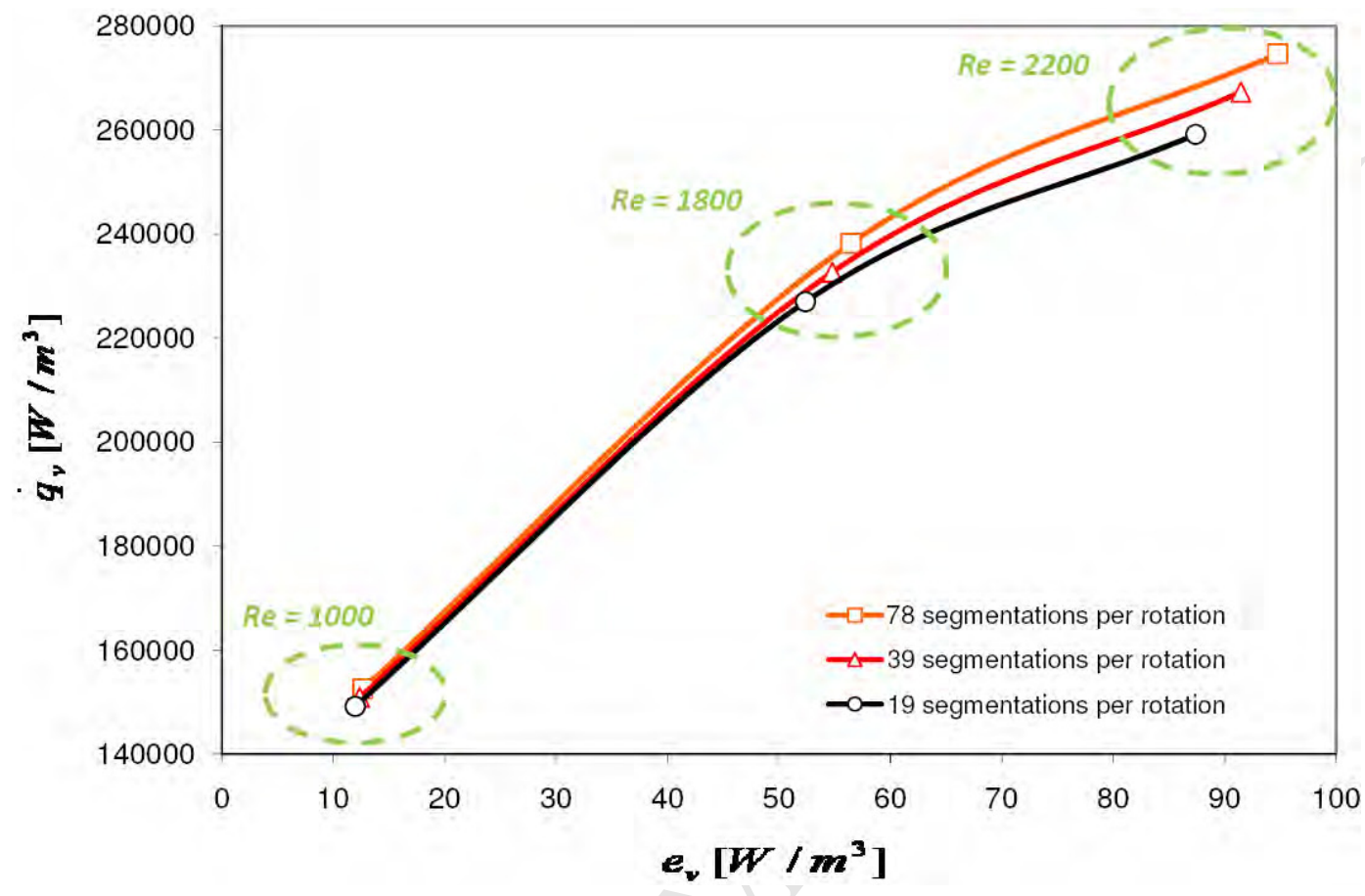

Figure 11: Performance plot for configurations with different number of segments per period and different Reynolds numbers. 

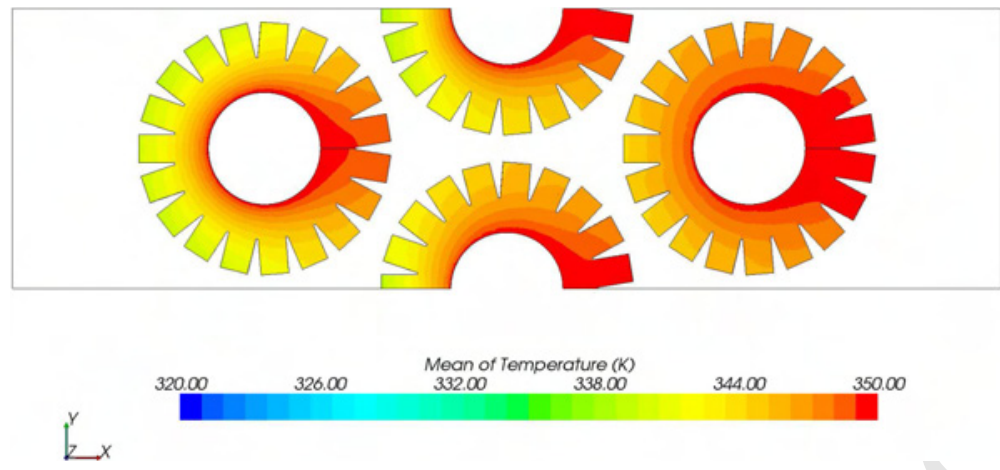

(a) Model with 19 segments per period
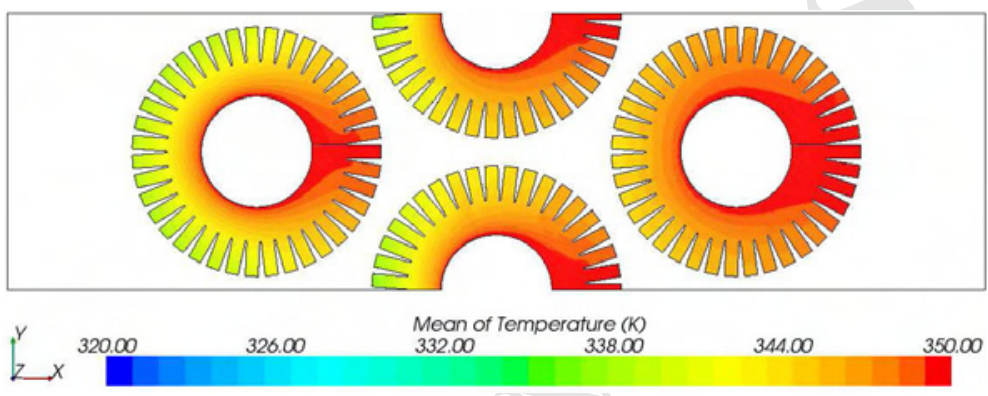

(b) Model with 39 segments per period
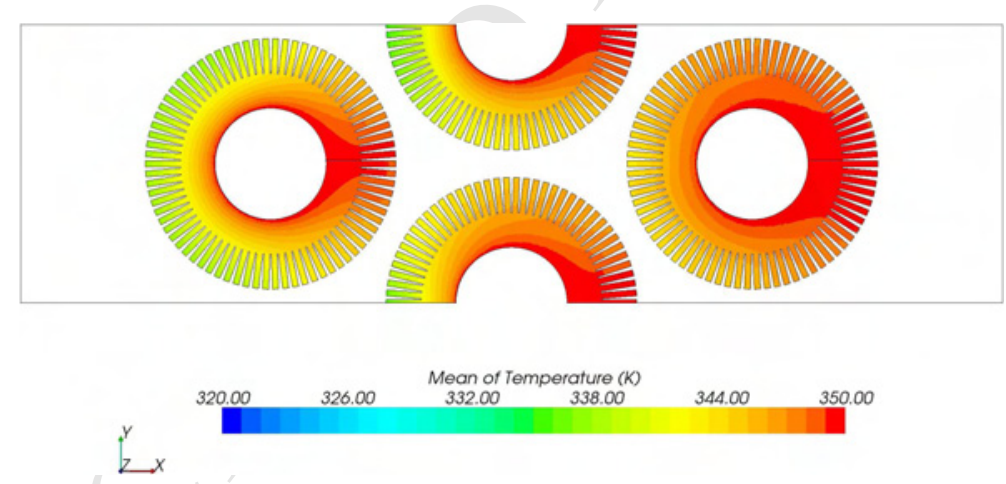

(c) Model with 78 segments per period

Figure 12: Time-averaged temperature distribution in the fins for different number of segments per period. 


\section{Tables}

Table 1: Dimensions of the main elements of the reference model.

Table 1: Dimensions of the main elements of the reference model.

\begin{tabular}{|l|c|l|}
\hline Dimension & Notation & Measure in $\mathrm{mm}$ \\
\hline Tube diameter & $d$ & 25.4 \\
\hline Outer fin diameter & $D$ & $57.15(=2.25 d)$ \\
\hline Fin thickness & $s$ & 0.203 \\
\hline Fin pitch & $p$ & $2.54(=0.1 d)$ \\
\hline Tube spacing & $S_{d}$ & $63.5(=2.5 d)$ \\
\hline Total fin height & $h_{t}$ & $15.875(=0.5(D-d))$ \\
\hline Segment width & $w$ & 3 \\
\hline Height of the serrated part in a segment & $h_{s}$ & $7.938(=0.5 H)$ \\
\hline Height of non-serrated part of the fin (fin-strip) & $h_{f}$ & $7.938(=0.5 H)$ \\
\hline Fin angle & $\beta$ & 0 \\
\hline Number of segments per period & $N$ & 39 \\
\hline
\end{tabular}


Outlet

Wall (adiabatic, slip)

$($ Top + Bottom + Sides $)$

Solid-fluid interface

Inlet

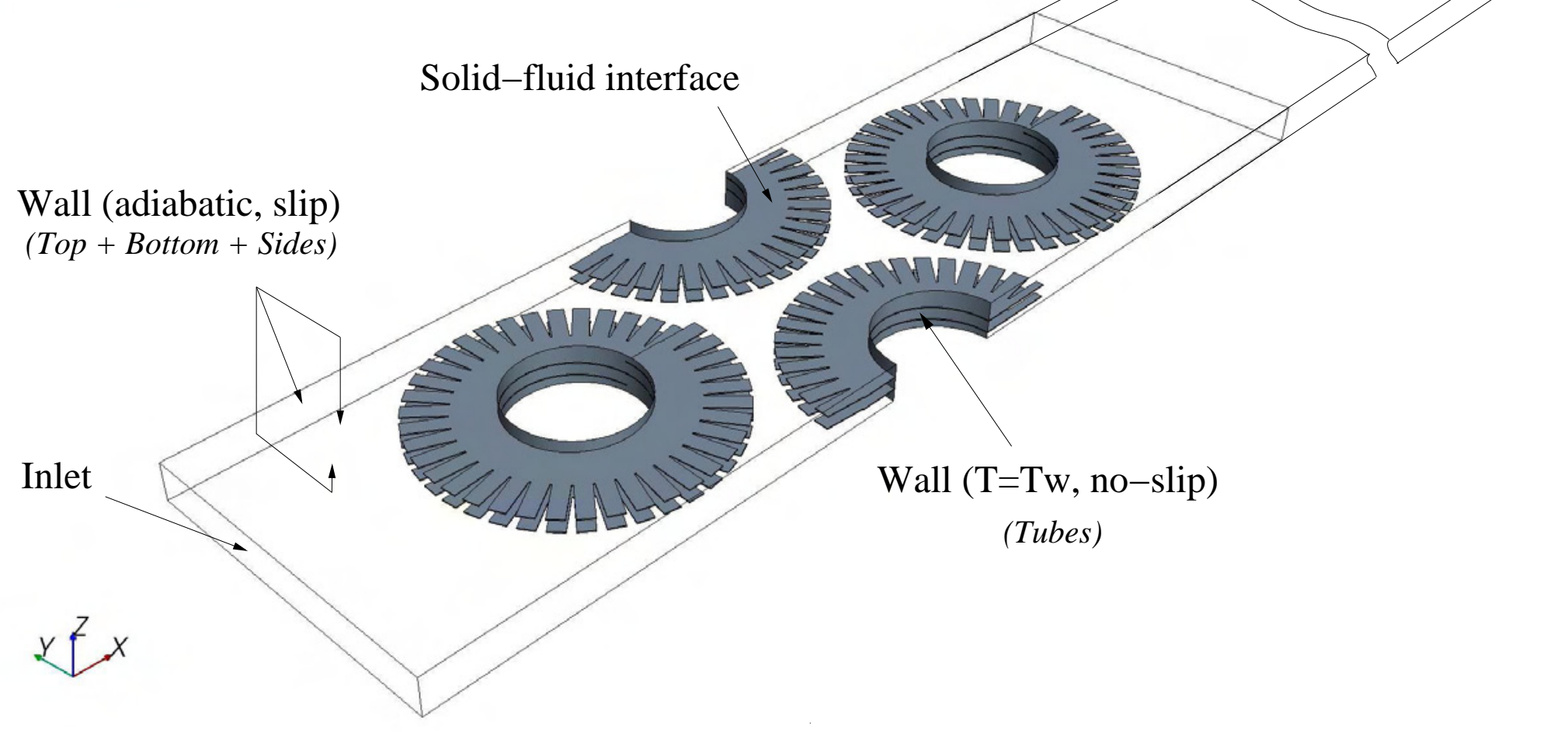


Figure(s)

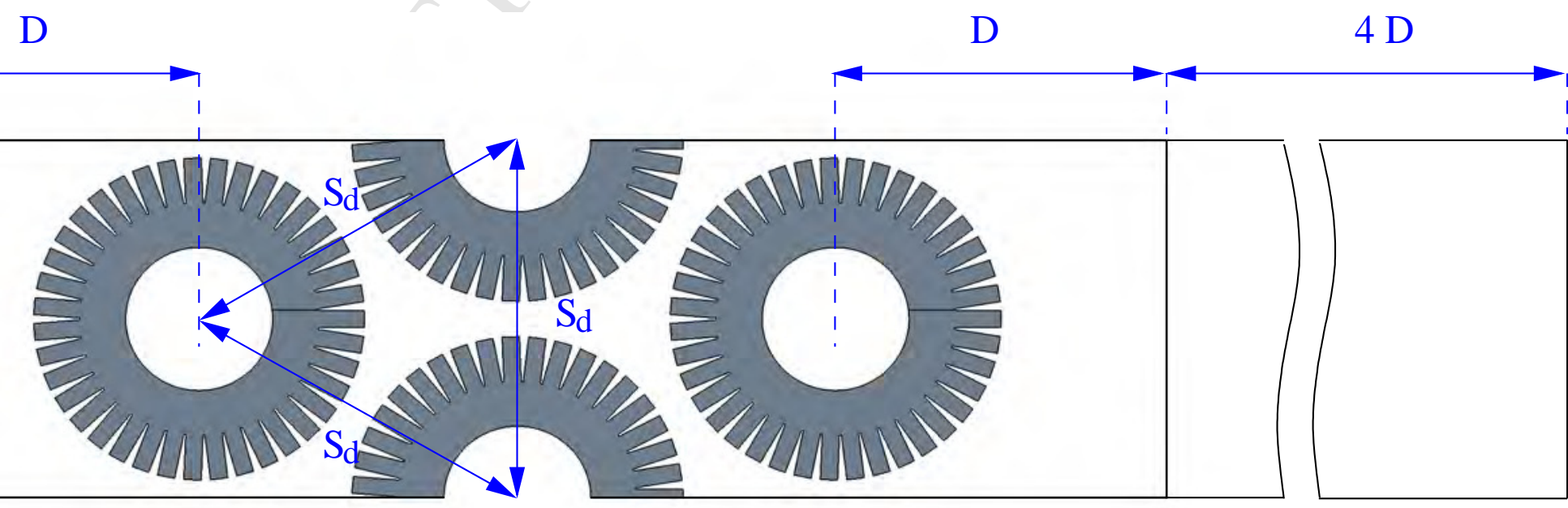



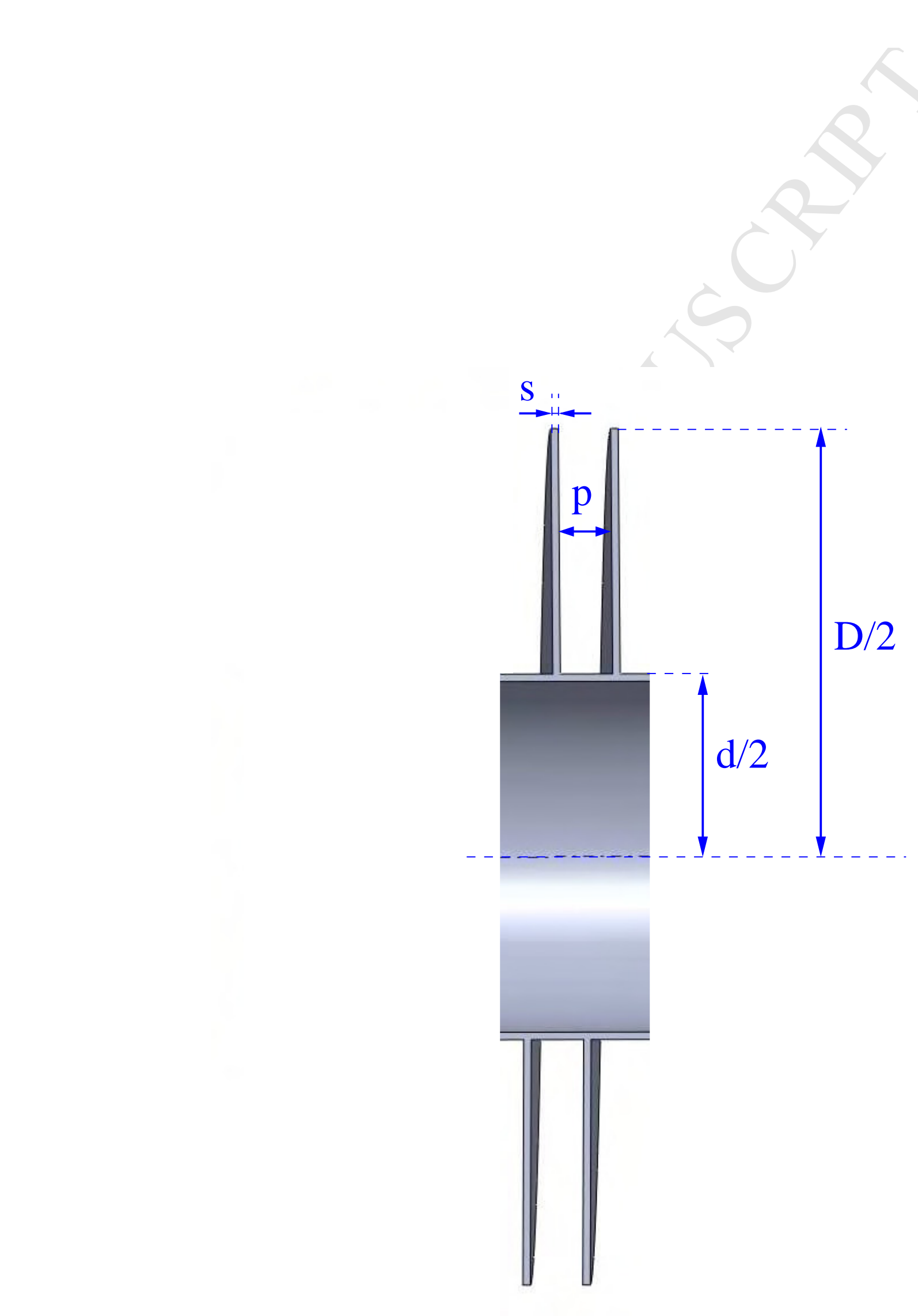

Figure(s) 


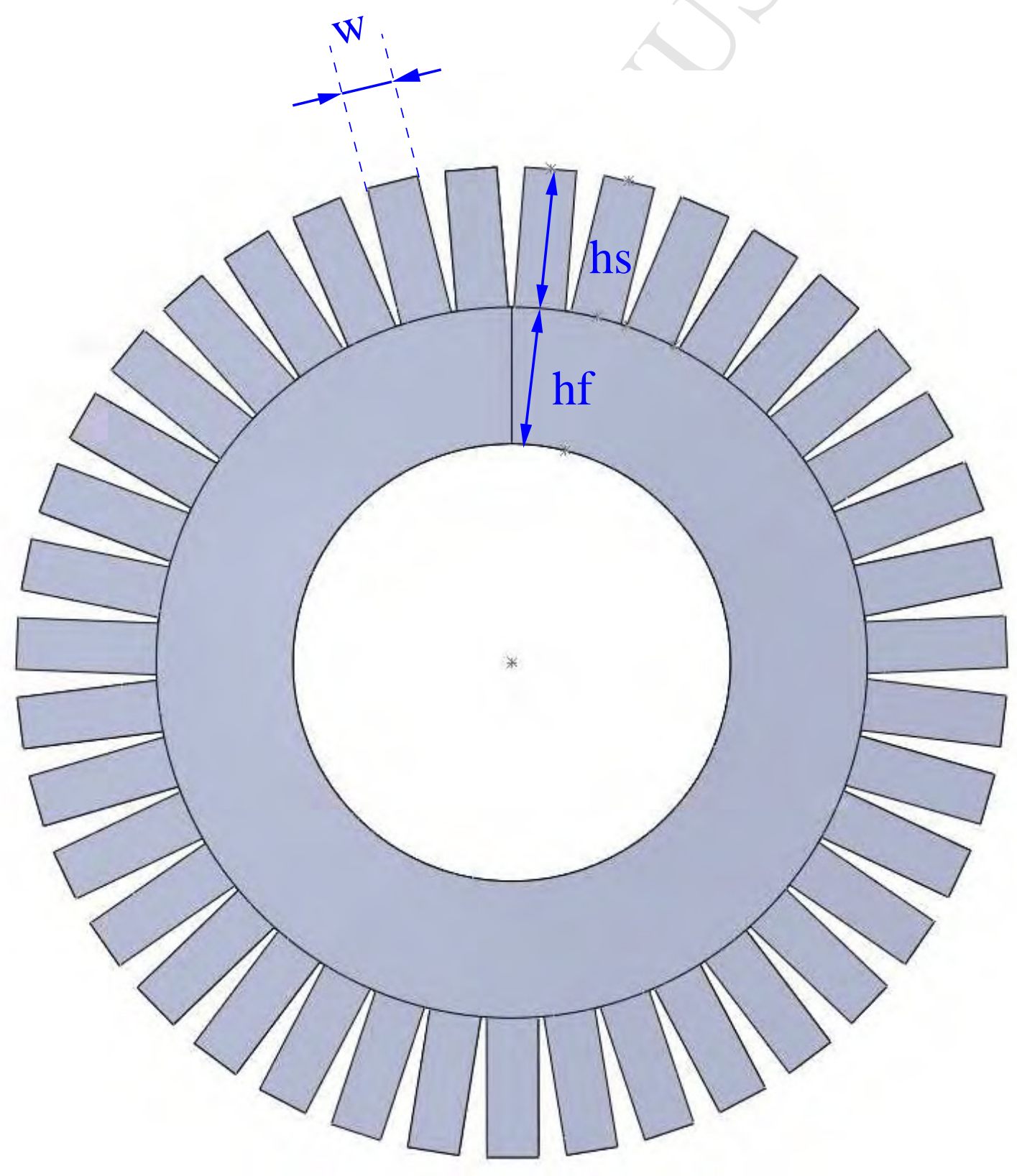





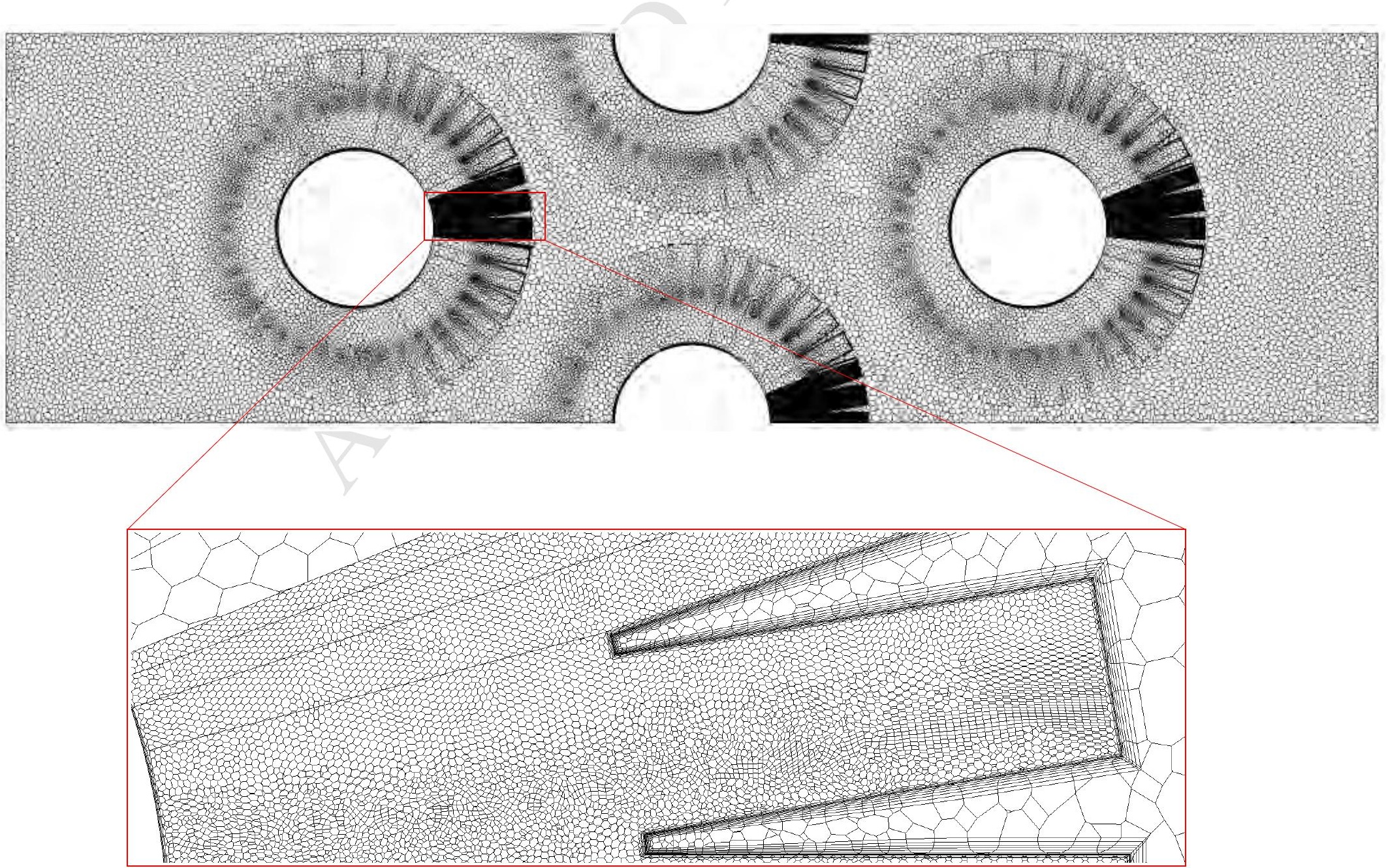




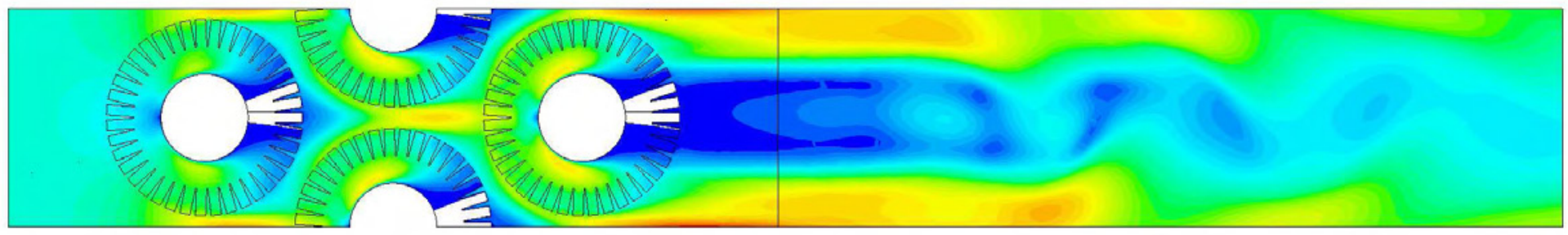

0.0000

Velocity: Magnitude $(\mathrm{m} / \mathrm{s})$

0.74809

1.1221

1.4962

1.8702 


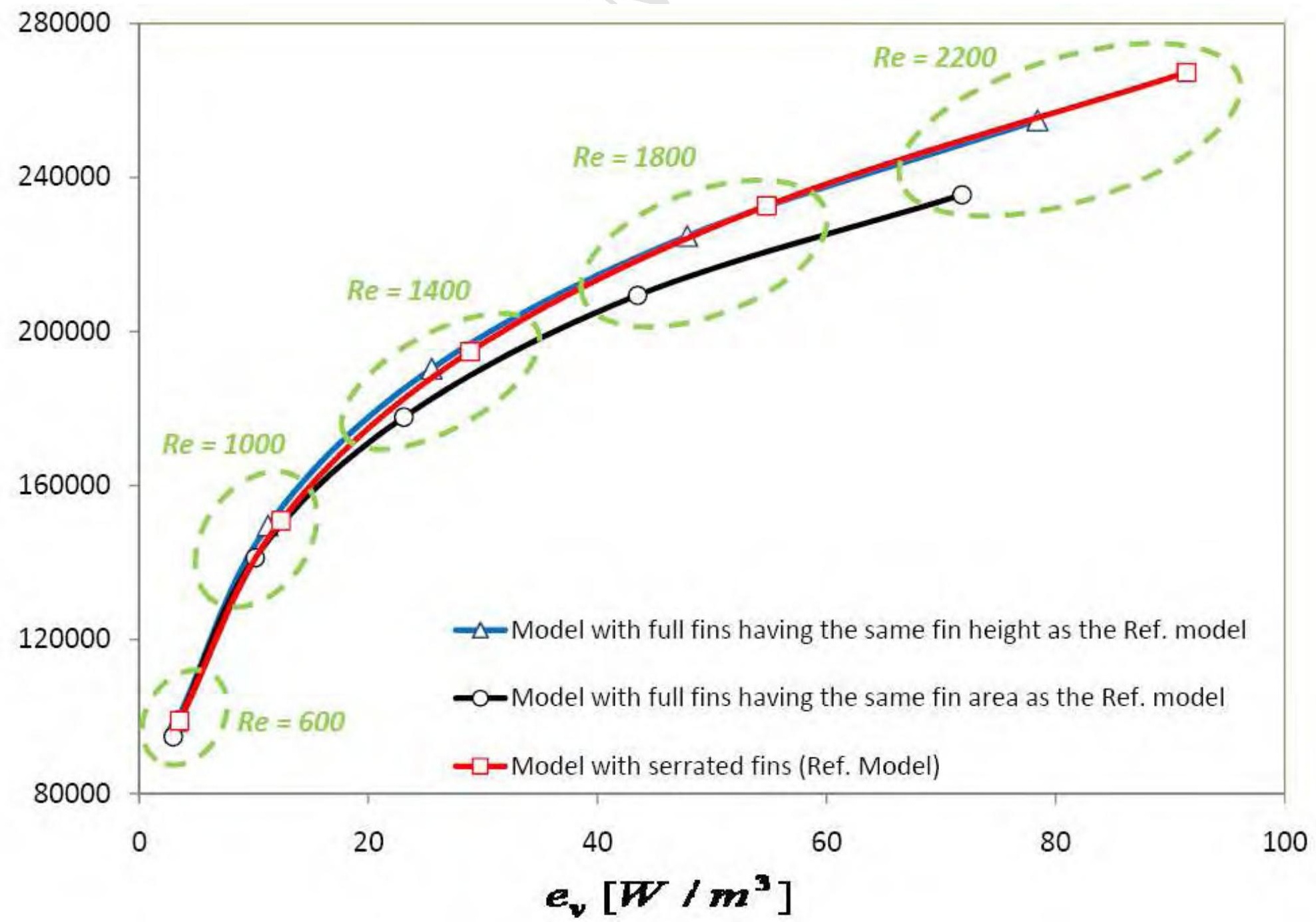




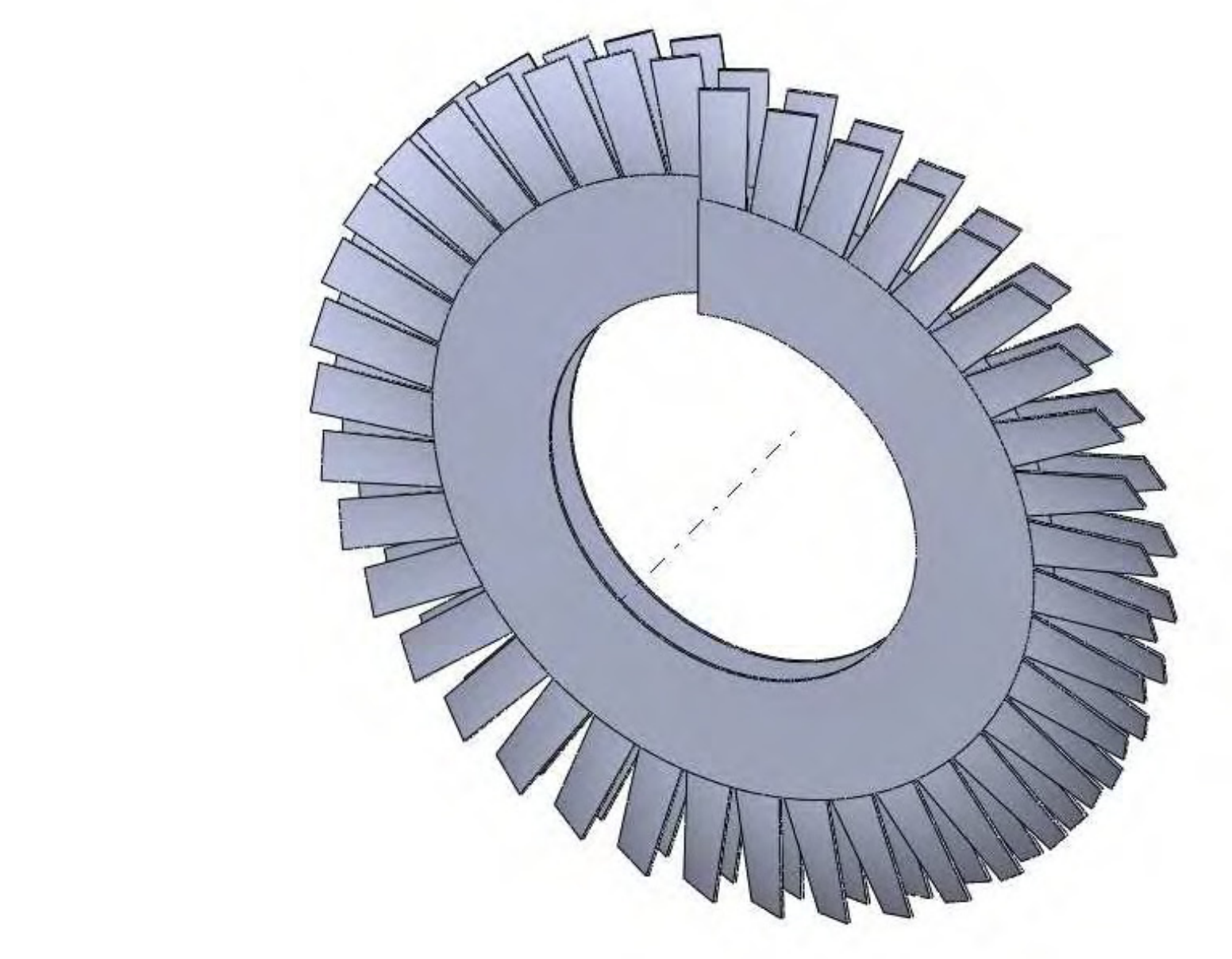

Figure(s)

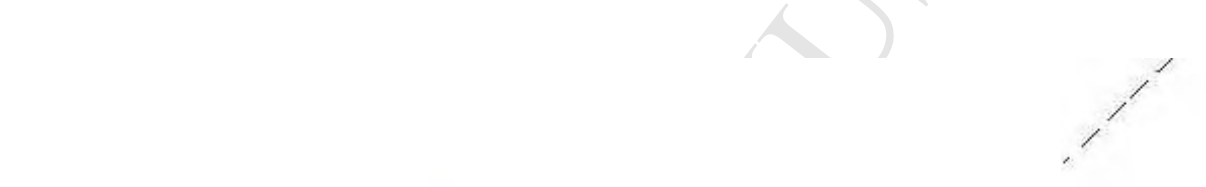

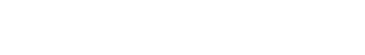


Figure(s)
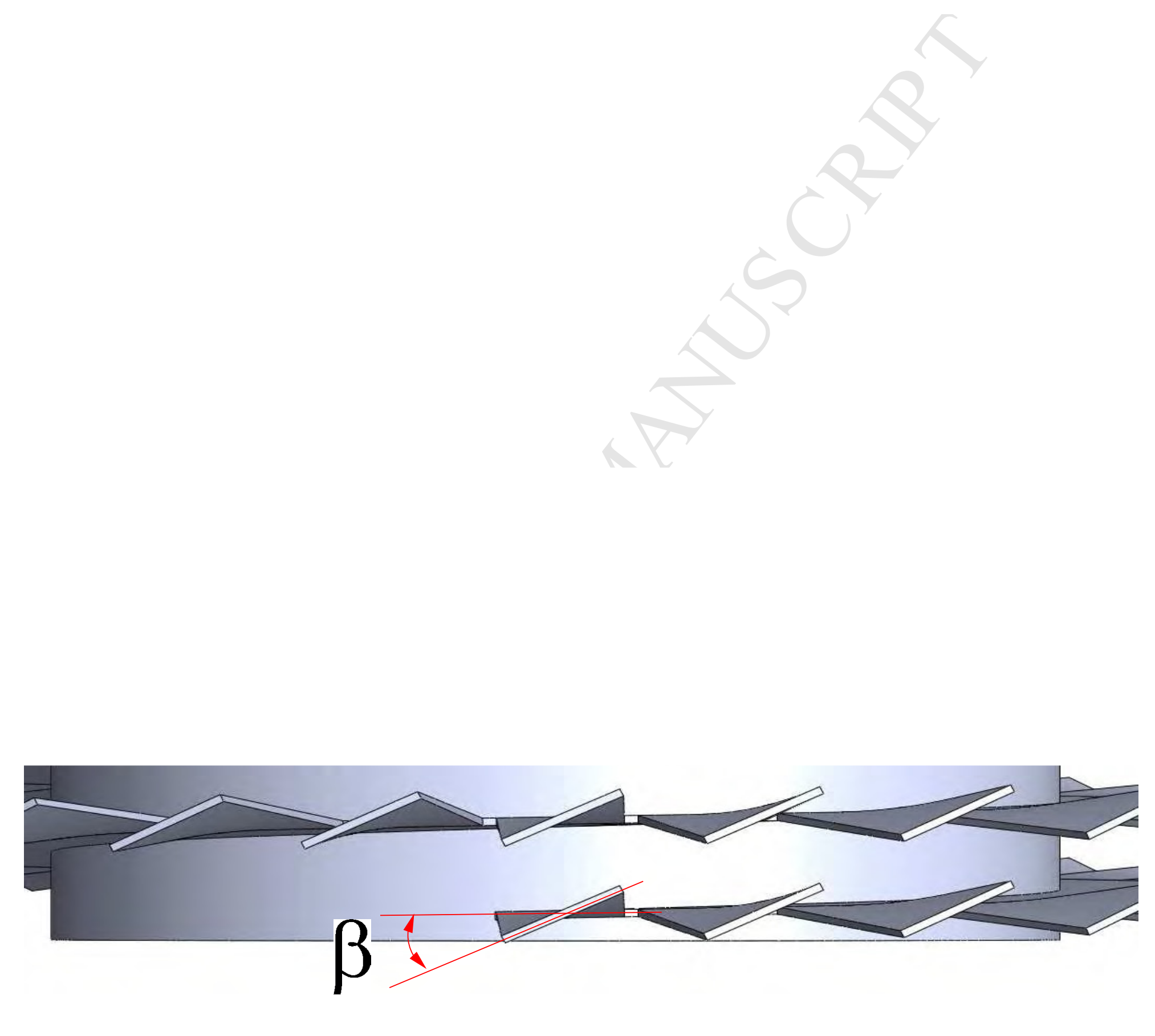

.

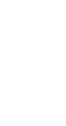


Figure(s)

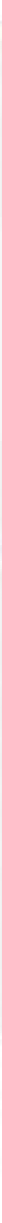


Figure(s)
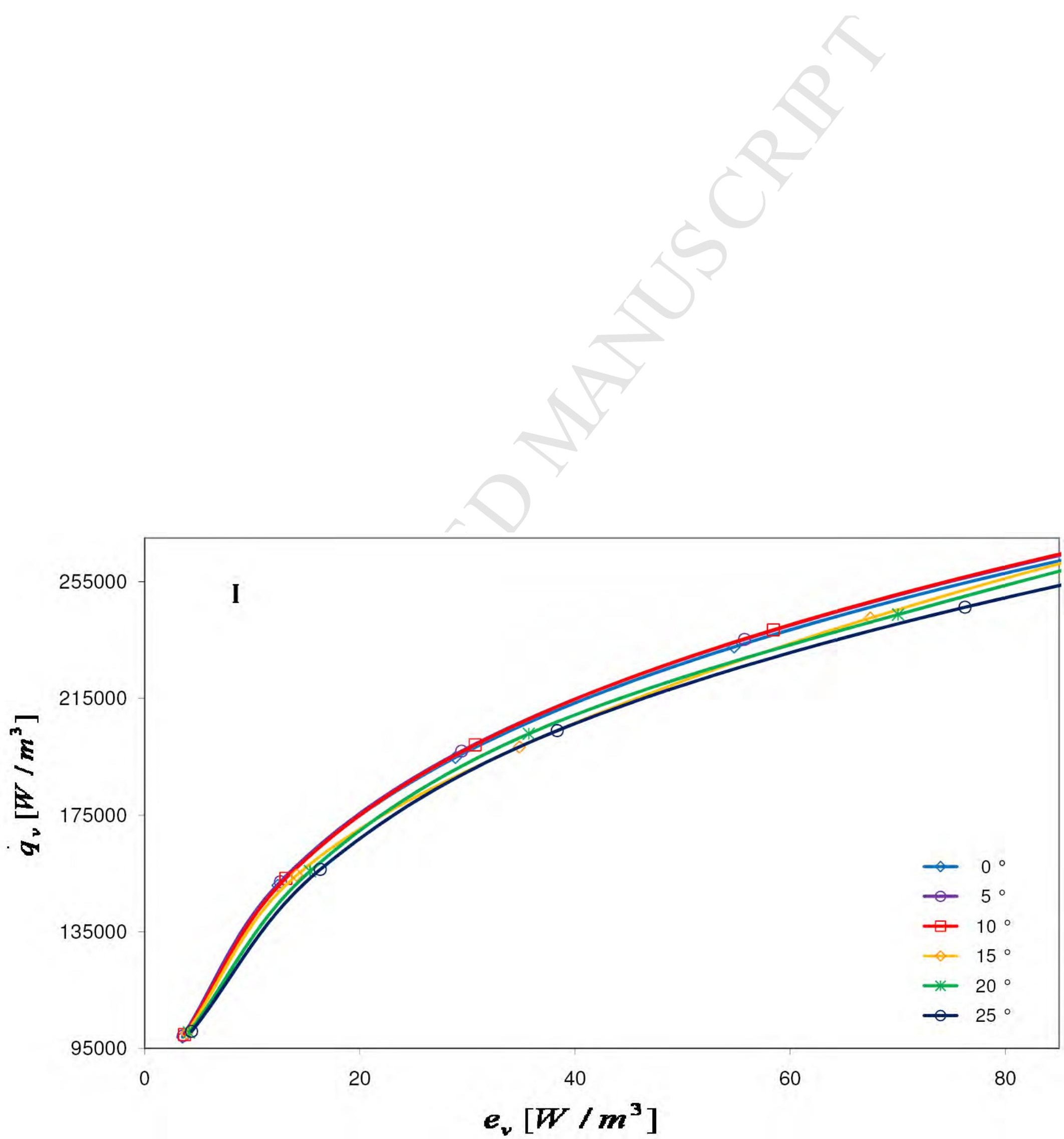
Figure(s)
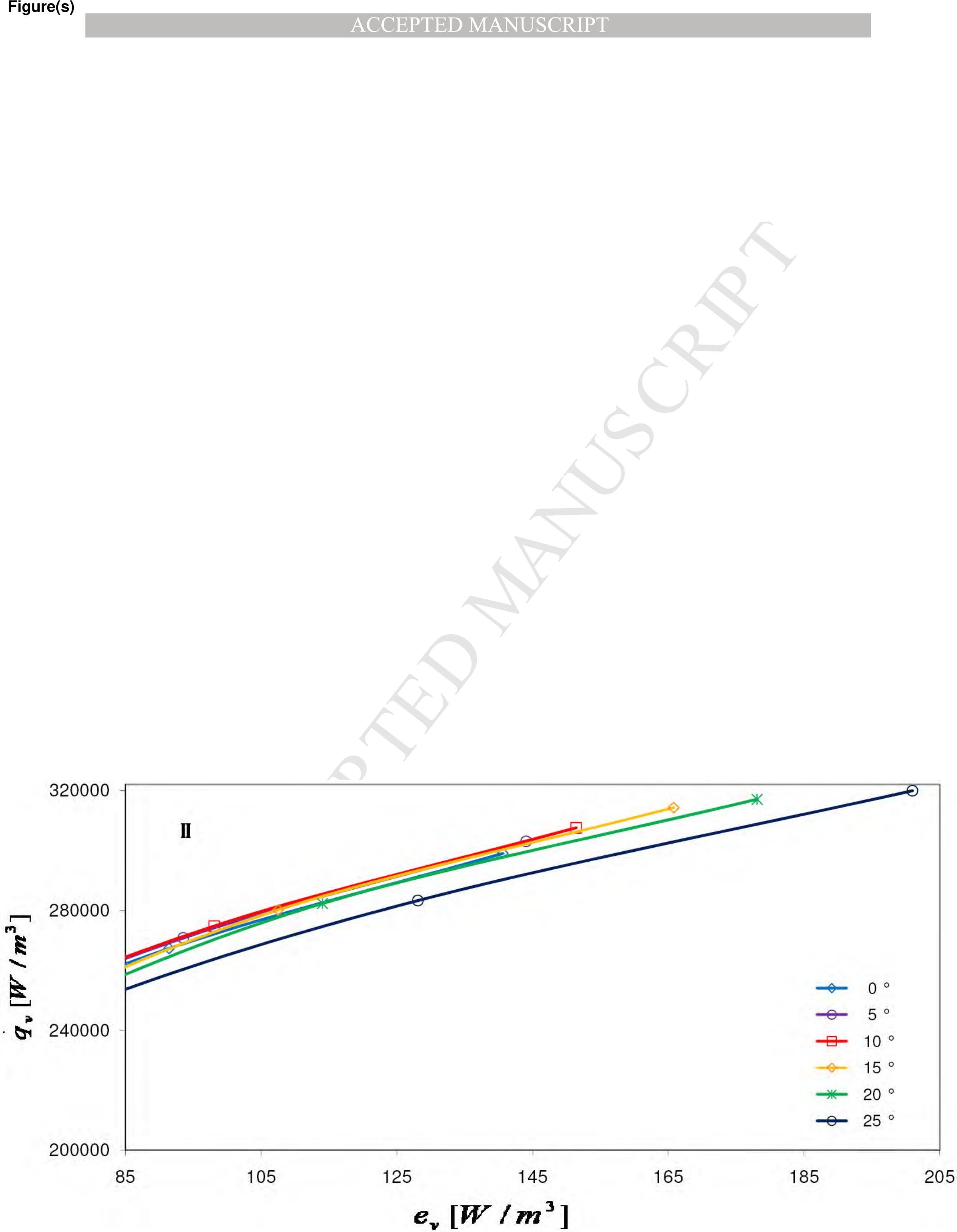


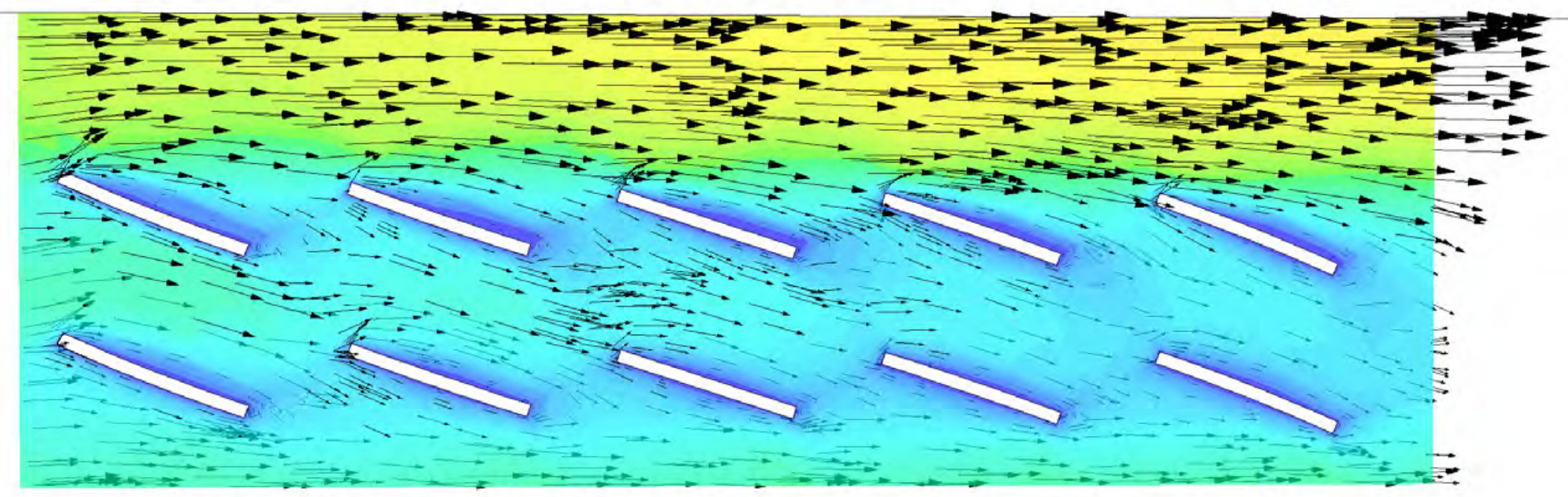




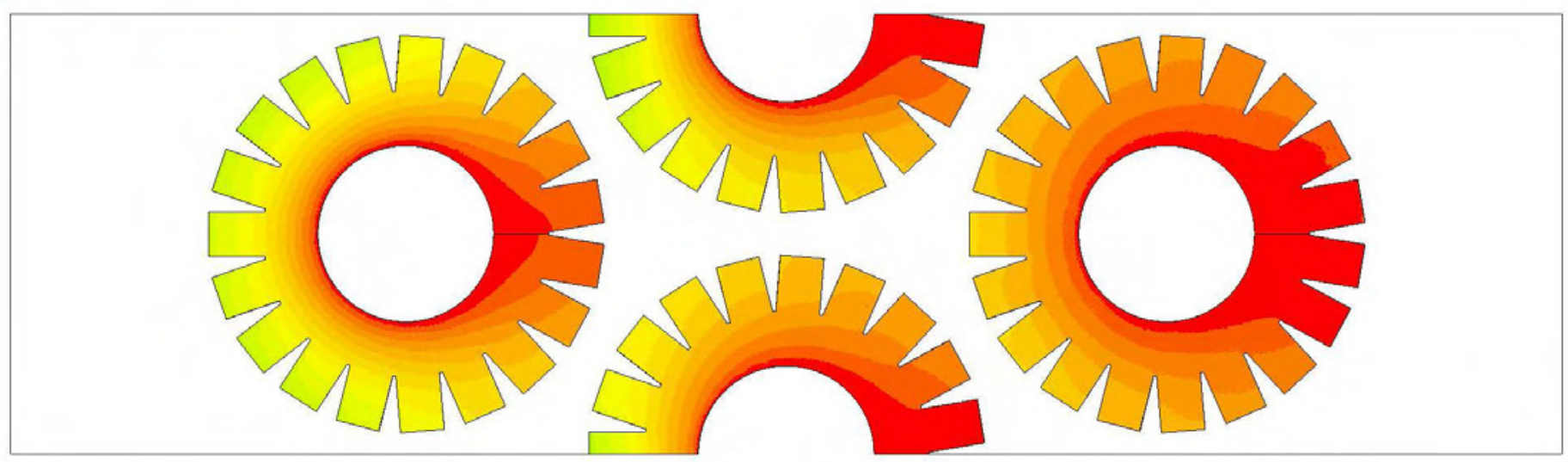

$$
320.00
$$


Figure(s)

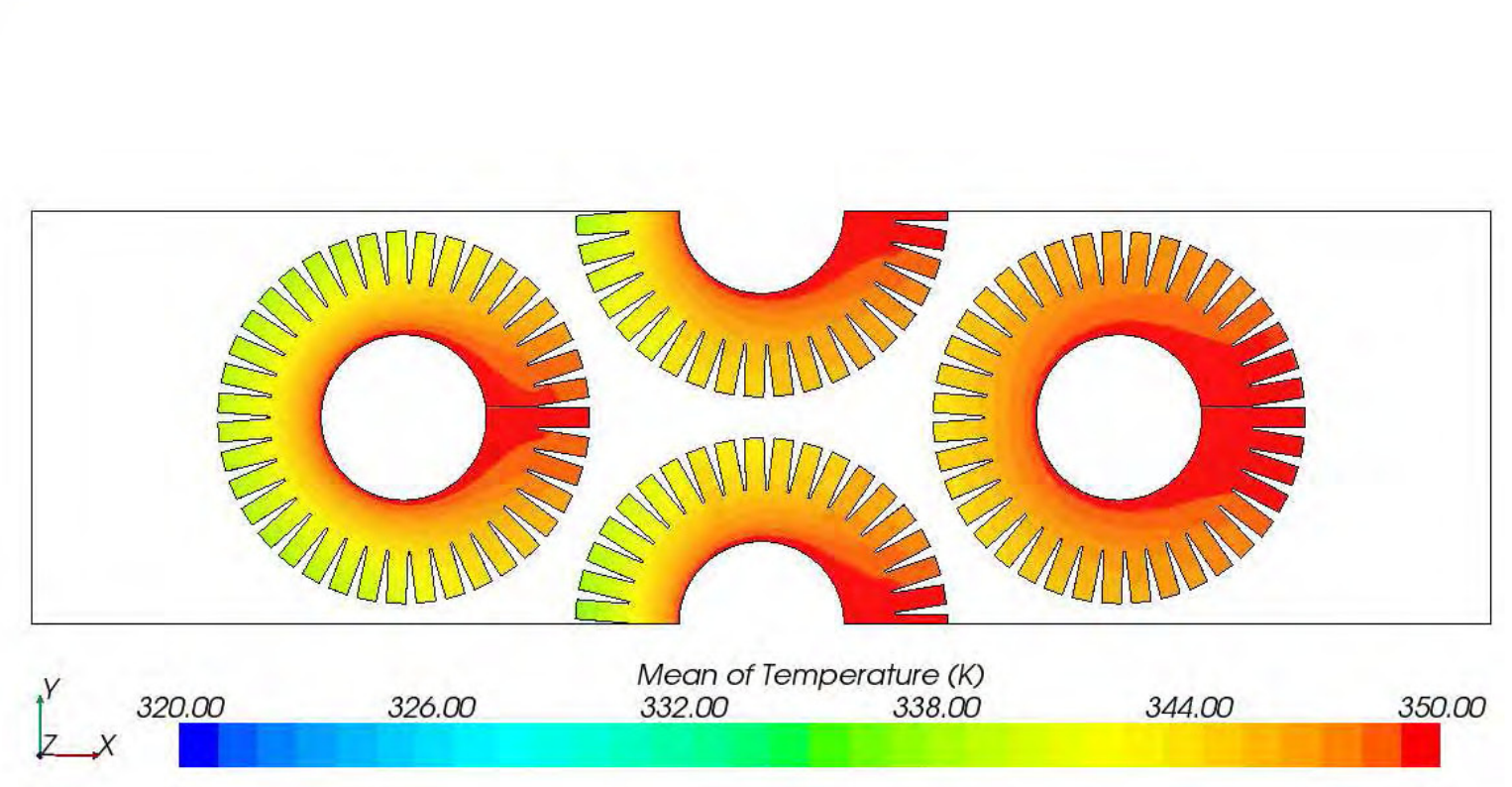



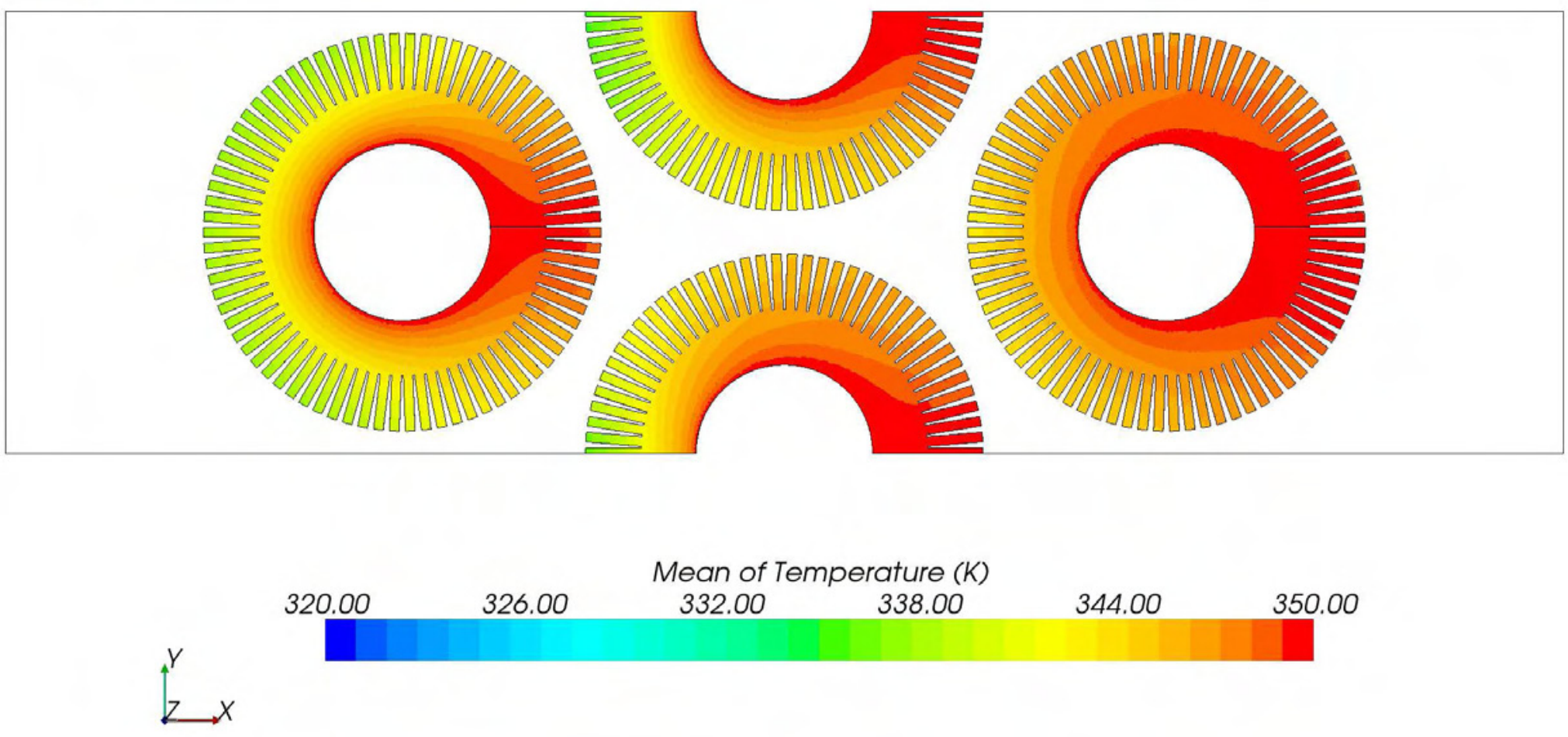

Mean of Temperature $(K)$

338.00

344.00

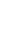

$Z x$ 